OPEN ACCESS

Edited by:

Brad Walters,

University of Mississippi Medical

Center, United States

Reviewed by:

Byron Haney Hartman,

Stanford University, United States

Amy Kiernan,

University of Rochester, United States

*Correspondence:

Brandon C. Cox

bcox@siumed.edu

Received: 30 January 2018 Accepted: 13 April 2018

Published: 04 May 2018

Citation:

McGovern MM, Zhou L, Randle MR and Cox BC (2018) Spontaneous

Hair Cell Regeneration Is Prevented by Increased Notch Signaling in Supporting Cells.

Front. Cell. Neurosci. 12:120. doi: 10.3389/fncel.2018.00120

\section{Spontaneous Hair Cell Regeneration Is Prevented by Increased Notch Signaling in Supporting Cells}

\author{
Melissa M. McGovern', Luyi Zhou', Michelle R. Randle' ${ }^{1}$ and Brandon C. Cox ${ }^{1,2 *}$ \\ 1 Department of Pharmacology, School of Medicine, Southern Illinois University, Springfield, IL, United States, ${ }^{2}$ Department \\ of Surgery, Division of Otolaryngology, School of Medicine, Southern Illinois University, Springfield, IL, United States
}

During embryonic development, differentiation of cochlear progenitor cells into hair cells (HCs) or supporting cells (SCs) is partially controlled through Notch signaling. Many studies have shown that inhibition of Notch signaling allows SCs to convert into HCs in both normal and drug damaged neonatal mouse cochleae. This mechanism is also implicated during $\mathrm{HC}$ regeneration in non-mammalian vertebrates; however, the mechanism of spontaneous $\mathrm{HC}$ regeneration in the neonatal mouse cochlea is less understood. While inhibition of Notch signaling can force SCs to convert into $\mathrm{HCs}$ and increase the number of regenerated HCs, it is currently unknown whether this pathway is involved in spontaneous $\mathrm{HC}$ regeneration observed in vivo. Therefore, we investigated the role of Notch signaling during the spontaneous $\mathrm{HC}$ regeneration process using Atoh1-CreER ${ }^{T M}::$ Rosa26 $6^{\text {loxP-stop-loxP-DTA } /+}$ mice injected with tamoxifen at postnatal day $(\mathrm{P}) \mathrm{O}$ and $\mathrm{P} 1$ to ablate $\mathrm{HCs}$ and stimulate spontaneous $\mathrm{HC}$ regeneration. Expression changes of genes in the Notch pathway were measured using immunostaining and in situ hybridization, with most changes observed in the apical one-third of the cochlea where the majority of $\mathrm{HC}$ regeneration occurs. Expression of the Notch target genes Hes1, Hes5, Hey1, HeyL, and Jagged1 were decreased. To investigate whether reduction of Notch signaling is involved in the spontaneous $\mathrm{HC}$ regeneration process, we overexpressed the Notch1 intracellular fragment (N1/CD) in cochlear SCs and other non-sensory epithelial cells in the context of $\mathrm{HC}$ damage. Specifically, Atoh1-CreERTM::Rosa26loxP-stop-loxP-DTA/+::Sox10'tTA ::TetO-LacZ::TetON1/CD mice were injected with tamoxifen at P0/P1 to stimulate spontaneous HC regeneration and given doxycycline from $\mathrm{PO}-\mathrm{P} 7$ to induce expression of $N 1 / C D$ as well as $L a c Z$ for fate-mapping. We observed a $92 \%$ reduction in the number of fate-mapped regenerated $\mathrm{HCs}$ in mice with N1/CD overexpression compared to controls with $\mathrm{HC}$ damage but no manipulation of Notch signaling. Therefore, we conclude that increased Notch signaling prevents spontaneous $\mathrm{HC}$ regeneration from occurring in the neonatal mouse cochlea. Understanding which components of the Notch pathway regulates regenerative plasticity in the neonatal mouse cochlea will inform investigations focused on stimulating $\mathrm{HC}$ regeneration in mature cochlea and eventually in humans to treat hearing loss.

\footnotetext{
Keywords: hair cell regeneration, cochlea, Notch, CreER, Tet-On, NICD
} 


\section{INTRODUCTION}

Hearing loss, one of the most prevalent conditions in the world, can result from multiple etiologies such as aging, viral infection, or exposure to noise or ototoxic drugs. In those born with normal hearing, death of sound-sensing hair cells (HCs) located within the cochlea is the most common source of hearing impairment. The mature mammalian cochlea does not regenerate HCs after damage, thus hearing loss is permanent (Bohne, 1976; Hawkins et al., 1976; Oesterle et al., 2008). However, in non-mammalian vertebrates, including birds, fish, and amphibians, the inner ear responds to damage by regenerating lost $\mathrm{HCs}$ throughout the life of the animal (reviewed in Bermingham-McDonogh and Rubel, 2003; Stone and Cotanche, 2007). Several studies have suggested that the Notch signaling pathway is involved in the HC regeneration process in non-mammals (reviewed in Stone and Cotanche, 2007; Brignull et al., 2009).

The Notch pathway uses membrane bound ligands and receptors expressed on adjacent cells to generate a mosaic pattern of cell types. In the mammalian cochlea, HCs and neighboring supporting cells (SCs) develop from the same pool of progenitor cells through a Notch-mediated process. As progenitor cells take a HC fate, they begin to express the Notch ligands Delta-like ligand 1 (Dll1), Delta-like ligand 3 (Dll3), and Jagged2 (Jag2) (Lanford et al., 1999, 2000; Morrison et al., 1999; Kiernan et al., 2005; Brooker et al., 2006; Hartman et al., 2007). These ligands signal to neighboring progenitor cells through Notch receptors which inhibits them from becoming HCs and instructs a SC fate (Lanford et al., 2000; Zheng et al., 2000; Zine et al., 2001; Murata et al., 2006; Hayashi et al., 2008; Doetzlhofer et al., 2009). A recent study reported limited down-regulation of Notch target genes after HC damage in the neonatal mouse cochlea (Korrapati et al., 2013). However, inhibition of the Notch signaling pathway, using pharmacological agents or genetically modified mouse models, in the late embryonic and early postnatal cochlea has the consistent effect of inducing the conversion of SCs into HCs either in the undamaged cochlea (Yamamoto et al., 2006; Doetzlhofer et al., 2009; Li et al., 2015; Maass et al., 2015) or after HC loss (Korrapati et al., 2013; Mizutari et al., 2013; Bramhall et al., 2014; Hu et al., 2016). Therefore, active Notch signaling in SCs plays an important role in maintaining their cell fate in the neonatal cochlea.

Recently, several groups have demonstrated that the immature murine cochlea has the capacity to spontaneously regenerate HCs during the first postnatal week (Bramhall et al., 2014; Cox et al., 2014; Hu et al., 2016) and loss of Notch signaling has been shown to increase the degree of $\mathrm{HC}$ regeneration over that which occurs spontaneously in HC damaged cochlear explants (Korrapati et al., 2013; Bramhall et al., 2014; Hu et al., 2016). While these results demonstrate that SCs can be forced to convert into HCs through inhibition of the Notch pathway, it is unclear whether the Notch signaling pathway is involved in the mechanism of spontaneous $\mathrm{HC}$ regeneration. To address this question, we first investigated changes in Notch signaling during the spontaneous $\mathrm{HC}$ regeneration process in the neonatal mouse cochlea and found that the expression of the Notch target genes Hes1, Hes5, Hey1, HeyL, and Jagged1 (Jag1) were decreased.
Next, to determine whether the spontaneous HC regeneration process is inhibited by sustained Notch signaling, we combined HC damage with overexpression of the Notch1 intracellular domain (NIICD) in SCs and other non-sensory epithelial cells and measured the effect on spontaneous $\mathrm{HC}$ regeneration. This model showed a $92 \%$ reduction in the number of spontaneously regenerated $\mathrm{HCs}$ and suggests that weakened Notch signaling contributes to SC plasticity which underlies spontaneous HC regeneration.

\section{MATERIALS AND METHODS}

\section{Animals}

Plp-CreER $R^{T 2}$ mice (Jax stock \#5975, Doerflinger et al., 2003), Rosa26 loxP-stop-loxP-DTA mice (Jax stock \#6331, Ivanova et al.,

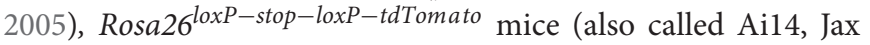
stock \#7914, Madisen et al., 2010), and TetO-LacZ mice (Jax stock \#2621, Furth et al., 1994), were obtained from The Jackson Laboratory (Bar Harbor, ME). Atoh1-CreER ${ }^{T M}$ mice (Chow et al., 2006) were provided by Dr. Suzanne Baker (St. Jude Children's Hospital, Memphis, TN, United States); Hes $5^{\text {LacZ }}$ mice (Imayoshi et al., 2010) were provided by Dr. Ryoichiro Kageyama (Kyoto University, Kyoto, Japan); Sox10 $10^{r t T A}$ mice (Ludwig et al., 2004; Walters and Zuo, 2015) were provided by Dr. Michael Wegner (Erlangen University, Erlangen, Germany); and TetO-N1ICD mice (Stanger et al., 2005) were provided by Dr. Ben Stranger (University of Pennsylvania, Philadelphia, PA, United States). Genotyping for all mouse lines was performed by Transnetyx, Inc. (Cordova, TN, United States). Mice of both genders were used in all studies and all animal work was performed in accordance with approved animal protocols from the Institutional Animal Care and Use Committee at Southern Illinois University School of Medicine.

\section{Substances Given to Animals}

To induce CreER recombination for either $\mathrm{HC}$ death or tdTomato expression, tamoxifen (Sigma-Aldrich, St. Louis, MO, United States) was dissolved in 100\% corn oil and injected intraperitoneally (IP) at $3 \mathrm{mg} / 40 \mathrm{~g}$ on either postnatal day (P) 0 , or both P0 and P1. To induce LacZ and N1ICD overexpression in cochlear SCs and other non-sensory epithelial cells, doxycycline (100 mg/kg, IP, Fisher, Hampton, NH, United States) was injected at P1 ( $\sim 6 \mathrm{~h}$ after the second tamoxifen injection) as well as administered in the food $(2000 \mathrm{mg} / \mathrm{kg}$, Envigo, Huntingdon, United Kingdom) to the nursing mother for the duration of the experiment.

\section{Real-Time qPCR}

Quantification of gene expression was conducted using real time quantitative polymerase chain reaction (qPCR). Neonatal pups were euthanized under isoflurane anesthesia (Henry Schein, Melville, NY, United States) and cochleae were collected from P7 animals, flash frozen in either liquid nitrogen or a dry ice slurry, and then stored at $-80^{\circ} \mathrm{C}$. Isolation of total RNA was conducted using tri-reagent (Fisher, Hampton, NH, United States), and precipitated with isopropanol (Acros Organics, Geel, Belgium) 
at $-20^{\circ} \mathrm{C}$ overnight followed by purification with DNAse treatment (cat \#AM1906, Fisher, Hampton, NH, United States) and reprecipitated using sodium acetate (Fisher, Hampton, NH, United States). Once total RNA was isolated, the concentration was measured using a Nanodrop 2000 (Fisher, Hampton, NH, United States) followed by reverse transcription into cDNA using Thermo Scientific Maxima First Strand cDNA synthesis kit (cat \#K1641, Fisher, Hampton, NH, United States) and stored at $-20^{\circ} \mathrm{C}$. The expression level of selected genes was measured from cDNA by qPCR using Sybr Green (cat \#K0391, Fisher, Hampton, NH, United States) and a CFX Connect Optics Module (Bio-Rad, Hercules, CA, United States). Comparison of gene expression among samples was conducted using the Pfaffl method which is a modified version of the delta-delta $C t$ equation that takes into account the efficiency of each primer set (Pfaffl, 2001). Gene expression was normalized to a housekeeping gene (Rpl19), which has been used previously for qPCR experiments in cochlear tissue (Basch et al., 2011; Korrapati et al., 2013; Wan et al., 2014; Maass et al., 2016). Data are expressed as fold change from control. Table 1 lists the primer sets used for each gene that was investigated and each primer set was tested for specificity with a reverse transcriptase-negative control to ensure they did not detect genomic DNA.

\section{Immunostaining}

Neonatal pups were euthanized under isoflurane anesthesia and cochleae were collected and post-fixed in $4 \%$ paraformaldehyde (Polysciences, Inc., Warrington, PA, United States) for $\sim 2 \mathrm{~h}$ at room temperature (RT). The samples were then transferred to $10 \mathrm{mM}$ Phosphate Buffered Saline (PBS, Sigma, St. Louis, $\mathrm{MO}$, United States) and stored at $4^{\circ} \mathrm{C}$. Following whole mount dissection, cochleae were cut into 3 turns of equal length and placed into a 48 well plate for immunostaining as free floating tissue. Samples were blocked and permeabilized at RT for $1 \mathrm{~h}$ with a solution of Normal Horse Serum or Normal Goat Serum (10\%, NHS, or NGS, Vector Labs, Burlingame, CA, United States), Bovine Serum Albumin (1\%, BSA, Fisher, Hampton, NH, United States), and Triton-X-100 (1\%, Sigma, St. Louis, MO, United States) in $10 \mathrm{mM}$ PBS prior to the application of the primary antibodies. Primary antibodies were diluted in a solution of $10 \mathrm{mM}$ PBS containing NHS or NGS (5\%), BSA (1\%), and Triton-X-100 (0.1\%) and incubated overnight at $4^{\circ} \mathrm{C}$ or $37^{\circ} \mathrm{C}$. The following primary antibodies were used: chicken anti$\beta$-galactosidase ( $\beta$-gal, 1:500, cat\#ab9361, Abcam, Cambridge, United Kingdom), goat anti-Jag1 (1:500, cat\#sc6011, Santa Cruz Biotechnology, Dallas, TX, United States), rabbit anti-myosin VIIa (1:200, cat\#25-6790, Proteus Biosciences, Ramona, CA,
United States), rabbit anti-S100a1 (1:1000, cat\#ab868, Abcam, Cambridge, United Kingdom), and goat anti-Sox2 (1:400, cat\#sc17320, Santa Cruz Biotechnology, Dallas, TX, United States). The next day, samples were washed three times with $10 \mathrm{mM}$ PBS for 5 min each at RT. Alexa fluor-conjugated secondary antibodies (Life Technologies, Waltham, MA, United States) were diluted $1: 1000$ in a solution of NHS or NGS (5\%), BSA (1\%), and Triton$\mathrm{X}-100(0.1 \%)$ in $10 \mathrm{mM}$ PBS and incubated for $\sim 3 \mathrm{~h}$ in the dark at RT. Following the secondary antibodies, samples were washed three times for $5 \mathrm{~min}$ each in $10 \mathrm{mM}$ PBS followed by a 20-min incubation with Hoechst (1:2000, Fisher, Hampton, $\mathrm{NH}$, United States) and three more, 5-min washes in $10 \mathrm{mM}$ PBS at RT. Following immunofluorescent labeling, samples were mounted on slides in Prolong Gold (Fisher, Hampton, NH, United States).

Additionally, chicken anti- $\beta$-gal antibodies produced excessive background and therefore to increase the signal to noise ratio, signal enhancer (enough volume to cover each sample, cat\#R37107, Thermo Fisher Scientific, Hampton, NH, United States) was applied at RT for 30 min followed by three 5-min PBS washes prior to the blocking/permeabilization step. A low $\mathrm{pH}$ antigen unmasking solution (AUM, cat\#H-3300, Vector Labs, Burlingame, CA, United States) was beneficial to increase antibody binding to the epitope for the antiJag1 antibodies. For this step, samples were incubated in a hybridization oven at $95^{\circ} \mathrm{C}$ for 45 min with a 1:100 dilution of the AUM solution in $\mathrm{ddH}_{2} \mathrm{O}$ followed by three 5 -min washes in $10 \mathrm{mM}$ PBS prior to blocking/permeabilization.

Imaging was conducted using a Leica SP5 or a Zeiss LSM 800 confocal microscope and images were processed with LAS-lite (Leica, Wetzlar, Germany) or Zen Blue lite (Zeiss, Oberkochen, Germany) software.

\section{In Situ Hybridization}

Probes were prepared by transfecting plasmids containing the full-length mouse cDNA sequences for Hes1 (Accession: BC051428, Clone ID: 6478994, Dharmacon, Inc., Lafayette, CO, United States), Hes5 (Accession: BC103539, Clone ID: 40039948, Dharmacon, Inc., Lafayette, CO, United States), Hey1 (Accession: BC086635, Clone ID: 6809680, Dharmacon, Inc., Lafayette, CO, United States), and HeyL (Accession: BC130263, Clone ID: 40142873, Dharmacon, Inc., Lafayette, CO, United States) into competent Escherichia coli cells (Fisher, Hampton, NH, United States) and incubating for $1 \mathrm{~h}$ at $37^{\circ} \mathrm{C}$ before spreading the cells on an agar plate containing the appropriate selection marker and incubating overnight. Once a clone was selected, it was inoculated with the appropriate selection antibiotic

TABLE 1 | Primer sets used for qPCR of Notch effector genes.

\begin{tabular}{llll}
\hline Gene & Forward primer & Reverse primer & Reference \\
\hline Hes1 & TCAACACGACACCGGACAAAC & ATGCCGGGAGCTATCTTCTT & Chonko et al., 2013 \\
Hes5 & GCACCAGCCCAACTCCAA & GGCGAAGGCTTGCTGTGT & White et al., 2006 \\
Hey1 & CACTGCAGGAGGGAAAGGTAT & CCCCAAACTCCGATAGTCCAT & Korrapati et al., 2013 \\
HeyL & GCGCAGAGGGATCATAGAGAA & TCGCAATCAGAAAGGCTACTG & Korrapati et al., 2013 \\
N1ICD & GACAACTCCTACCTCTGCTTATGCC & TACTGTTGCACTCGTGACCTCG & Yamamoto et al., 2006
\end{tabular}


and incubated overnight in $250 \mathrm{ml}$ of media containing the selection marker at $37^{\circ} \mathrm{C}$, after which cells were centrifuged and the supernatant was decanted. The cells were processed with a ZymoPURE plasmid maxiprep kit (cat\#D4202, Zymo Research, Irvine, CA, United States) to isolate the plasmid DNA. Concentration was measured on a Nanodrop 2000 (Fisher, Hampton, NH, United States) and the plasmids were linearized and cleaned up with phenol::chloroform::isoamyl alcohol (Fisher, Hampton, NH, United States). Plasmids were sequenced by GenScript (Piscataway, NJ, United States) and each sequence was entered into BLAST (NCBI, Bethesda, MD, United States) to determine their correspondence to the endogenous mouse mRNA sequence $($ Hes $1=97.4 \%$ homology, Hes5 $=100 \%$ homology, Heyl $=99.9 \%$ homology, and HeyL $=99.5 \%$ homology). Then the probes were digoxigenin-labeled (DIG; cat\# 286036 910, Roche, Indianapolis, IN, United States) through in vitro transcription and cut into $\sim 300$ bp pieces though a mild alkaline bath to facilitate interaction with the endogenous RNA.

Cochleae were fixed in RNase free $4 \%$ paraformaldehyde (PFA; Polysciences, Inc., Warrington, PA, United States) for $\sim 2 \mathrm{~h}$ at RT or overnight at $4^{\circ} \mathrm{C}$. Following fixation, cochleae were dissected and dehydrated in a graded methanol series (Fisher, Hampton, NH, United States) for $5 \mathrm{~min}$ in each concentration $[25,50,75$, and $100 \%$ diluted in RNase free $10 \mathrm{mM}$ PBS with $0.1 \%$ Tween-20 (PTw) (Sigma, St. Louis, MO, United States)]. Samples were rehydrated through a reverse graded methanol series and transferred to RNase free $2 \mathrm{ml}$ tubes. Samples were washed three times for $5 \mathrm{~min}$ each in RNase free PTw at RT. Next, samples were digested for $15 \mathrm{~min}$ at RT with $10 \mu \mathrm{g} / \mathrm{ml}$ proteinase $\mathrm{K}$ (Fisher, Hampton, $\mathrm{NH}$, United States) in PTw then incubated with 4\% PFA containing $0.2 \%$ glutaraldehyde (Sigma, St. Louis, MO, United States) for $20 \mathrm{~min}$ to halt the digestion. Then samples were again washed twice with RNase free PTw for $5 \mathrm{~min}$ each. Next, hybridization buffer $[50 \%$ formamide (Sigma St. Louis, MO, United States), $1.5 \times$ saline-sodium citrate (SSC, Sigma, St. Louis, MO, United States), $\mathrm{pH}$ adjusted to 4.5 with citric acid (Sigma, St. Louis, MO, United States), $50 \mu \mathrm{g} / \mathrm{ml}$ yeast tRNA (Sigma, St. Louis MO, United States), $100 \mu \mathrm{g} / \mathrm{ml}$ heparin (Sigma, St. Louis, MO, United States), 0.2\% Tween-20 (Sigma, St. Louis, MO, United States), 0.5\% CHAPS (3-[(3Cholamidopropyl)dimethylammonio]-1-propanesulfonate hydrate Sigma, St. Louis, MO, United States), and 5mM EDTA pH 8.0, (Millipore, Billerica, MA, United States)] was added to each sample and incubated at $60^{\circ} \mathrm{C}$ for $3 \mathrm{~h}$ followed by the addition of the DIG-labeled riboprobe to the hybridization buffer at a concentration of $0.5 \mu \mathrm{g} / \mathrm{ml}$ (Hes5) or $1 \mu \mathrm{g} / \mathrm{ml}$ (Hes1, Heyl, and $\mathrm{HeyL}$ ) and incubated at $60^{\circ} \mathrm{C}$ overnight.

The following day, samples were rinsed twice $(\sim 1$ min each $)$ with hybridization buffer and washed twice $(30 \mathrm{~min}$ each) with hybridization buffer at $60^{\circ} \mathrm{C}$. Samples were then washed with a 1:1 mixture of hybridization buffer and 1X MABT [maleic acid buffer containing Tween-20, 5X stock concentration of $500 \mathrm{mM}$ maleic acid (Sigma, St. Louis, MO, United States), $744 \mathrm{mM} \mathrm{NaCl}$ (Sigma, St. Louis, MO, United States), $44 \mathrm{mM}$ Tween-20 (Sigma, St. Louis, MO, United States) and $\mathrm{ddH}_{2} \mathrm{O}$ and $\mathrm{pH}$ adjusted with Tris Base (Roche, Indianapolis, IN,
United States) to $\sim 7.5$ ] for $20 \mathrm{~min}$ at $60^{\circ} \mathrm{C}$. Samples were then rinsed three times $(\sim 1$ min each) with $1 \mathrm{X}$ MABT and washed twice (30 min each) with $1 \mathrm{X}$ MABT at RT. Samples were blocked with $1 \mathrm{X}$ MABT containing $20 \%$ sheep serum (Sigma, St. Louis, MO, United States) and 2\% Boehringer blocking reagent (Sigma, St. Louis, MO, United States) for $3 \mathrm{~h}$ at RT. Next the samples were incubated overnight at $4^{\circ} \mathrm{C}$ with anti-digoxigenin antibodies (cat\#11093274910, Sigma, St. Louis, MO, United States) in 1X MABT at a final concentration of 1:2000.

The following day, samples were rinsed three times $(\sim 1 \mathrm{~min}$ each) with $1 \mathrm{X}$ MABT and then washed three times $(1 \mathrm{~h}$ each) with $1 \mathrm{X}$ MABT at RT followed by an overnight wash at $4^{\circ} \mathrm{C}$. Samples were then washed twice with alkaline phosphatase buffer [100 mM Tris (Sigma, St. Louis, MO, United States) $\mathrm{pH}$ 9.5, $50 \mathrm{mM} \mathrm{MgCl}_{2}$ (Fisher, Hampton, $\mathrm{NH}$, United States), $100 \mathrm{mM} \mathrm{NaCl}$ (Sigma, St. Louis, MO, United States), and $0.1 \%$ Tween-20 (Sigma, St. Louis, MO, United States)] for $1 \mathrm{~h}$ each and then processed with $4.5 \mu \mathrm{l} / \mathrm{ml}$ nitro-blue tetrazolium (Sigma, St. Louis, MO, United States) and $3.5 \mu \mathrm{l} / \mathrm{ml}$ 5-bromo-4-chloro-3'-indolyphosphate (Sigma, St. Louis, MO, United States) in alkaline phosphatase buffer in the dark between 2 and $20 \mathrm{~h}$. Samples were then washed twice in alkaline phosphatase buffer (5 min each), washed three times in PTw (1 h each), and fixed in 4\% PFA for $30 \mathrm{~min}$. Samples were then cleared in $60 \%$ glycerol overnight and mounted on slides in $100 \%$ glycerol (Fisher, Hampton, $\mathrm{NH}$, United States) and imaged with a Neurolucida system (MicroBrightField, Inc., United States) integrated with a Zeiss AxioImager M2 microscope (Carl Zeiss Microscopy, Germany) or an Olympus IX70 microscope (Olympus Corporation, Waltham, MA, United States). All in situ experiments were performed with matched experimental and control samples from the same litter run in parallel.

\section{Quantification and Statistical Analysis}

For quantification of Sox2-positive and Hes5-LacZ-positive cells, images were taken from two representative regions in the apical turn of the cochlea and cells in either a $150 \mu \mathrm{m}$ or $200 \mu \mathrm{m}$ region per image were quantified and averaged for each sample. Positive expression of LacZ was determined by the overlap of LacZ labeling and nuclear staining with Hoechst once antibody background was reduced using the imaging software. The same trained examiner counted images for both control and experimental samples to make sure that the same threshold for positive staining was maintained. To quantify the amount of $\mathrm{HC}$ regeneration (LacZ-positive HCs) in the model where NIICD was overexpressed, images of the entire cochlea were taken using tile scan with z-series. Each cochlea was measured and divided into six equal sections as previously described (McGovern et al., 2017). For quantification of $\mathrm{HCs}$ in cochlea overexpressing N1ICD, $200 \mu \mathrm{m}$ regions were selected from two representative images per cochlear turn and total HCs were quantified and averaged. All data are presented as mean \pm standard error of the mean (SEM). Data was analyzed using a one- or two-way ANOVA or a Student's $t$-test with Graphpad Prism 6.02 (Graphpad Software Inc., La Jolla, CA, United States). 


\section{RESULTS}

\section{Hes5 Expression Is Reduced During Spontaneous HC Regeneration}

Because the majority of spontaneously regenerated HCs are formed in the apical turn of the cochlea (Cox et al., 2014), we investigated gene changes in this region at the cellular level. We first measured changes in the expression of Hes5, a direct inhibitor of HC fate that is a well-known target of active Notch signaling (Mulvaney and Dabdoub, 2012; Abdolazimi et al., 2016). Hes5 is expressed in many SC subtypes during the first postnatal week including Deiters' cells, outer pillar cells, inner phalangeal cells, border cells, and some cells of the greater epithelial ridge (GER) (Figures 1A-C,G-I,M-O, 2B-B"',D-D"',F-F"'; Lanford et al., 2000; Zine et al., 2001; Hartman et al., 2009; Cox et al., 2014; Maass et al., 2015). To quantify the number of cells that express Hes5, we used the Hes5 $5^{\text {LacZ }}$ reporter line which has LacZ knocked into the endogenous Hes5 locus and therefore is a faithful representation of endogenous Hes 5 expression (Imayoshi et al., 2010). Others have shown that $\beta$-galactosidase $(\beta$-gal), transcribed by the Lac $Z$ gene, continues to be expressed $\sim 1$ day after mRNA of the endogenous gene becomes undetectable (Morrison et al., 1999). Therefore, we used Hes5 $5^{\text {LacZ }}$ mice to approximate the window when cells lose Hes5 expression. Atoh1-CreER ${ }^{T M}:: R o s a 26^{\text {loxP-stop-loxP-DTA mice (hereinafter }}$ referred to as Atoh1-DTA mice) were bred with $H e s 5^{\text {LacZ }}$ mice and injected with tamoxifen ( $3 \mathrm{mg} / 40 \mathrm{~g}$, IP) on both P0 and P1 to induce $\mathrm{HC}$ ablation and initiate spontaneous $\mathrm{HC}$ regeneration. Samples were analyzed at P2, P4, and P6, which was previously established as the window of spontaneous $\mathrm{HC}$ regeneration seen in the neonatal mouse cochlea (Cox et al., 2014). We quantified the number of cells that expressed Hes5-LacZ as well as the number of SC and immature HC nuclei using anti-Sox2 antibodies. Significantly fewer Hes5-LacZ-positive cells were detected in the Atoh1-DTA::Hes5 ${ }^{\text {LacZ }}$ cochlea at P2 $(216.1 \pm 12.3$ vs. $107.3 \pm 19.1 ; p<0.001 ; N=3)$ and $\mathrm{P} 4$ (185.6 \pm 13.3 vs. $115.5 \pm 14.1 ; p<0.01$ as determined by a two-way ANOVA with a Tukey's post hoc test; $N=3$ ) compared to control samples that lacked either the Atoh1-CreER ${ }^{T M}$ or $R o s a 26^{D T A}$ allele (Figures 1A-L,S). However, there was no difference observed in Hes5-LacZ expression at P6 (140.1 \pm 11.6 vs. $120.3 \pm 7.3$; $N=4$; Figures $\mathbf{1 M - S}$ ). There were also no differences in the number of Sox2-positive cells after $\mathrm{HC}$ damage at any age (Figures 1B,E,H,K,N,Q,S) suggesting that as a whole, the Sox2-positive cell population is not reduced.

Differences among SC subtypes have previously been documented (Lanford et al., 2000; Doetzlhofer et al., 2009; Yu et al., 2010; Taylor et al., 2012; Lagarde et al., 2013; Maass et al., 2016), which may indicate that not all SC subtypes maintain plasticity postnatally. Furthermore, loss of Hes5 at embryonic ages has been implicated in the formation of supernumerary outer HCs, but not inner HCs (Zine et al., 2001). We therefore sought to investigate changes in Hes 5 expression within discrete SC subpopulations. To divide the SC subtypes into two groups, we used pillar and Deiters' cells as a landmark. S100a1 is a calcium binding protein that is expressed in the cytoplasm and nucleus of pillar and Deiters' cells within the neonatal cochlea (White et al., 2006; Buckiová and Syka, 2009). Therefore, combining anti-S100a1 antibodies with anti-Sox2 and anti$\beta$-gal antibodies allowed us to tease apart two groups of SC subpopulations: (1) pillar cells and Deiters' cells which are labeled by S100a1, and (2) inner phalangeal and border cells which are Hes $5^{\text {LacZ }}$-positive/Sox2-positive cells located medial to S100a1 labeling (Figures 2A-B','D-D”,'F-F”'). Because Hes $5^{\text {LacZ }}$ is also expressed in the cells of the GER, the medial border of inner phalangeal and border cells was established for quantification by measuring the width of tdTomato expression medial to inner pillar cells in $\mathrm{Plp}-\mathrm{CreER}^{T 2}:: R o s a 26^{\text {loxP-stop-loxP-tdTomato }}$ mice injected with tamoxifen ( $3 \mathrm{mg} / 40 \mathrm{~g}$, IP) at P0, which has previously been shown to target inner phalangeal and border cells, but not the GER (Supplementary Figures S1A-C; Doerflinger et al., 2003; Gómez-Casati et al., 2010; Cox et al., 2012; Mellado Lagarde et al., 2014; McGovern et al., 2017).

After HC damage and regeneration was induced in Atoh1DTA::Hes $5^{\text {LacZ }}$ mice by tamoxifen injection at P0 and $\mathrm{P} 1$, there was a significant decrease in the number of Hes5-LacZ-positive pillar and Deiters' cells detected at P2 (113.1 \pm 3.8 vs. $63.6 \pm 5.1$, $p<0.01, N=4), \mathrm{P} 4$ (104.4 \pm 1.5 vs. $42.1 \pm 5.7, p<0.001$, $N=4-5)$, and P6 (98.6 \pm 2.4 vs. $25.3 \pm 4.4, p<0.001, N=4)$ compared to control cochleae which lacked either the Atoh1CreER $R^{T M}$ or Rosa26 ${ }^{D T A}$ allele (Figures $2 \mathbf{B}-\mathbf{H}$ ). Of note, the number of Sox2-positive cells within this population did not decrease until P4 (140.2 \pm 3.1 vs. $98.1 \pm 11.5, p<0.001 ; N=4$ $5)$ and was also decreased at P6 (130.3 \pm 2.7 vs. $75.0 \pm 6.0$, $p<0.0001 ; N=4$; Figures 2B-H). Additionally, there was an increase in the number of Sox2-positive/Hes5-LacZ-negative pillar and Deiters' cells at P2 (39.0 \pm 1.6 vs. $102.2 \pm 21.9$, $p<0.001 ; N=4$; Figures $2 \mathbf{B}-\mathbf{H}$ ), suggesting that Hes5 is downregulated in these SCs, but the cells are still alive. In contrast, neither the number of Hes5-LacZ-positive cells, nor the number of Sox2-positive cells within the inner phalangeal and border cells region were significantly altered from control samples (Figures 2B-G'”,I), suggesting that weakened Notch signaling is limited to pillar and Deiters' cells during the $\mathrm{HC}$ regeneration process.

\section{Reduced Expression of Notch Effectors Hes1, Hes5, Hey1, and HeyL Was Observed During Spontaneous HC Regeneration}

Further changes in the expression of Notch target genes were investigated using in situ hybridization. Atoh1-DTA mice as well as littermate controls, which lacked the Atoh1-CreER ${ }^{T M}$ or Rosa $26^{D T A}$ allele, were injected with tamoxifen $(3 \mathrm{mg} / 40 \mathrm{~g}$, IP) on P0 and P1 to induce HC damage as well as spontaneous HC regeneration. Samples were collected and analyzed at P4 using probes that target Hes1, Hes5, Hey1, and HeyL. Paired samples from the same litter (control and Atoh1-DTA) were processed in parallel where each solution, as well as each incubation time, was identical. Comparisons were only made between the one experimental and the one control sample that were processed together. Staining intensity in the sensory 


\section{Atoh1-DTA::Hes5 ${ }^{\text {LacZ }}$

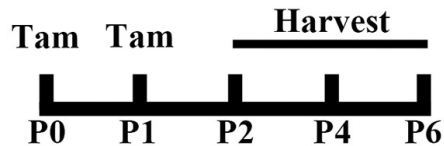

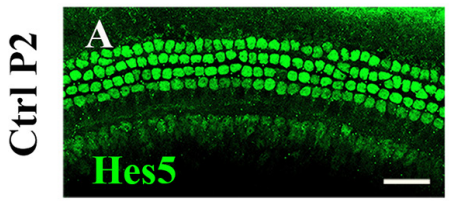
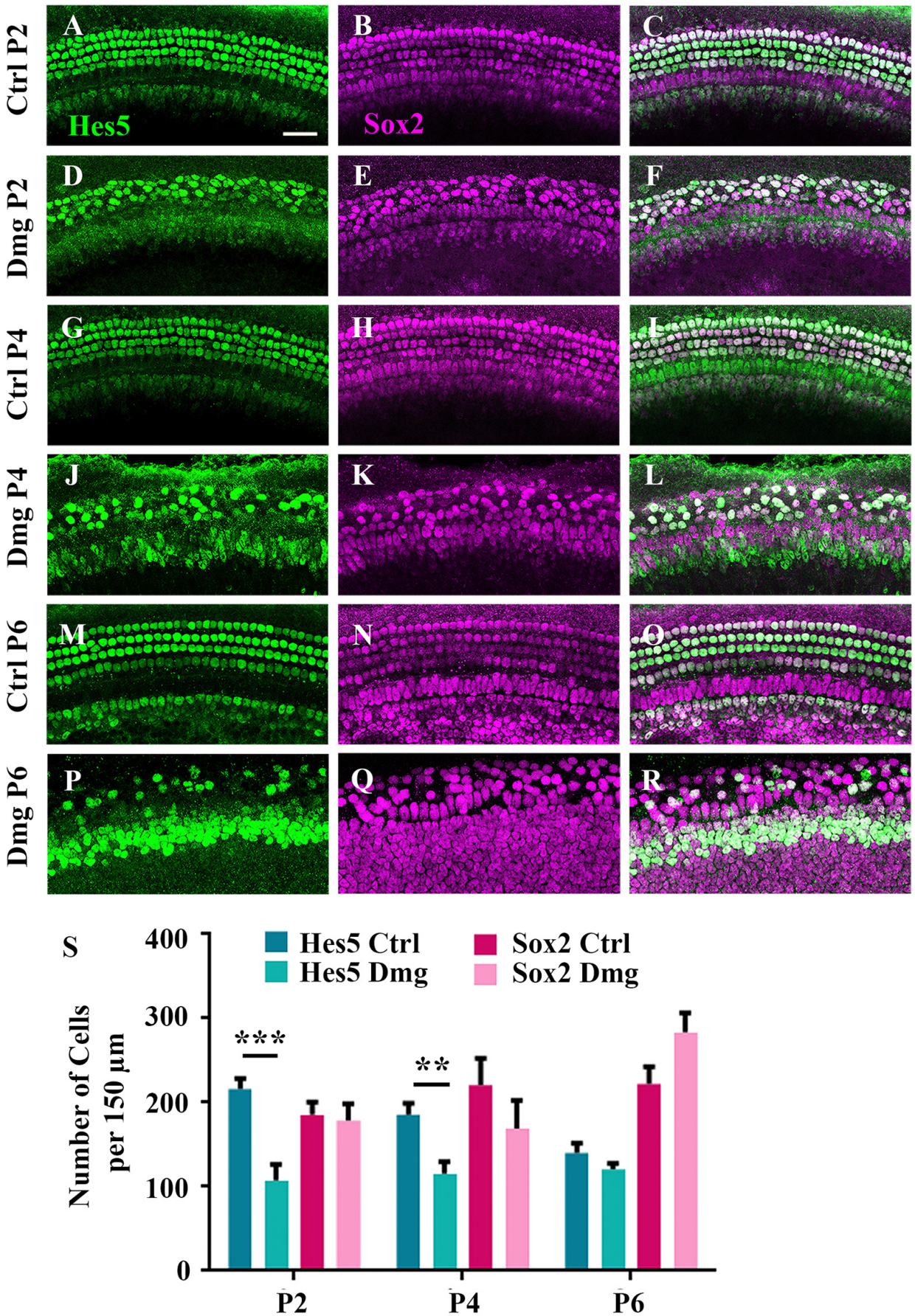

FIGURE 1 | Hes5-LacZ-positive cells, but not Sox2-positive cells, are reduced during the spontaneous HC regeneration process. Atoh1-DTA::Hes5 LacZ mice were injected with tamoxifen (Tam) at PO-P1 to induce HC death and spontaneous HC regeneration and cochleae were collected at P2, P4, and P6. (A-R) Representative confocal slice images with anti- $\beta$-gal antibodies to detect Hes5-LacZ expression (green) and anti-Sox2 antibodies to label all SC nuclei (magenta). (A-C, G-I, M-O) Images are taken from P2, P4, or P6 control samples, respectively. Scale bar $=25 \mu \mathrm{m}$. (S) Fewer Hes5-LacZ-positive cells were detected in HC damaged samples at P2 and P4, but not P6. There was no significant difference in the number of Sox2-positive cells in the Atoh1-DTA::Hes5 ${ }^{\text {LacZ }}$ cochlea after HC damage compared to undamaged controls. ${ }^{* *} p<0.01,{ }^{* * *} p<0.001$, as determined by a two-way ANOVA with a Sidak's post hoc test. $N=3-5$. 


\section{Atoh1-DTA::Hes5 $5^{\text {LacZ }}$}
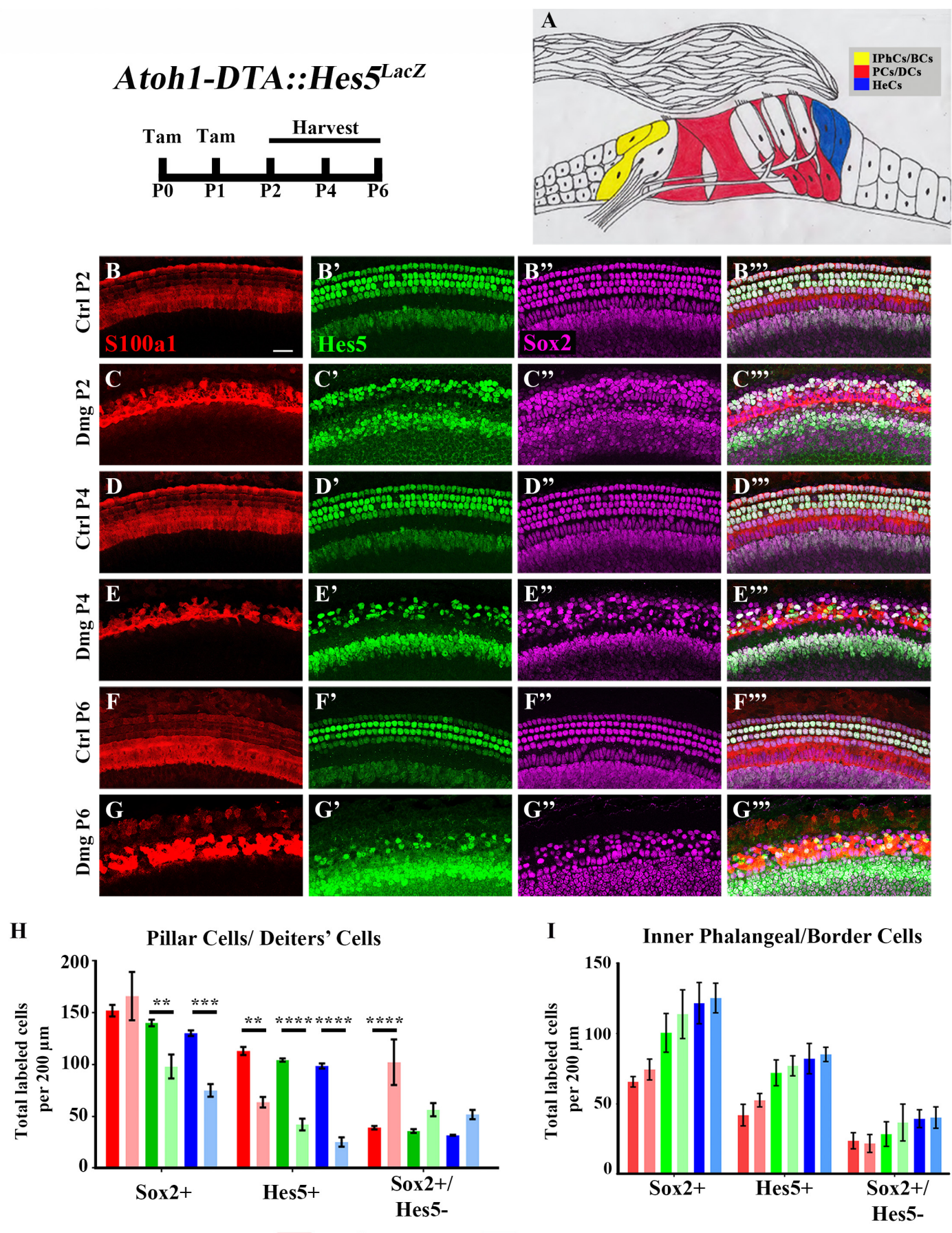

I Inner Phalangeal/Border Cells
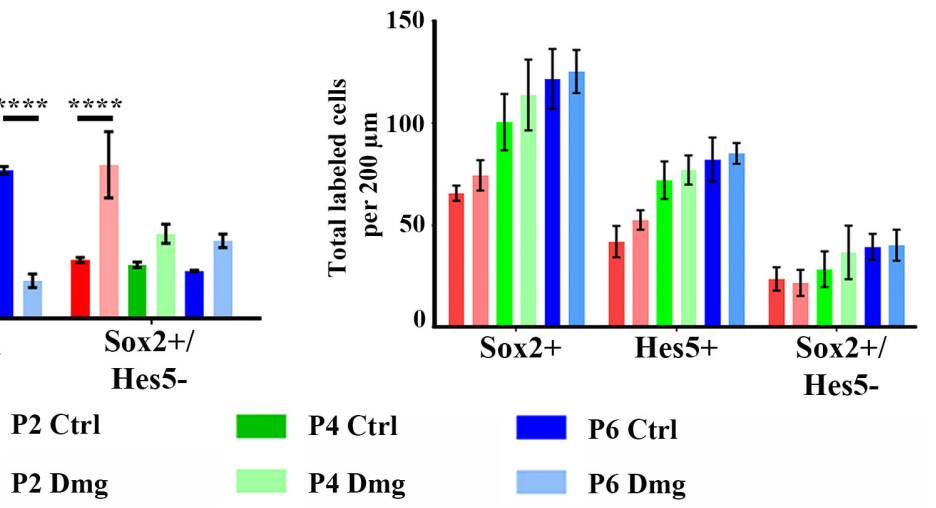

P4 Ctrl

P4 Dmg

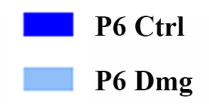

FIGURE 2 | Hes5-LacZ-positive cells are reduced in lateral SCs, but not medial SCs. (A) Pillar and Deiters' cells (red, PCs/DCs) are labeled with S100a1 and inner phalangeal/border cells (yellow, IPhCs/BCs) lie medial to the S100a1 expressing region. Hensen cells (blue, HeCs) express Sox2 and border the lateral edge of the S100a1 region, but do not have Hes5 expression. (B-G"') Atoh1-DTA::Hes5 ${ }^{\text {LacZ }}$ mice were injected with tamoxifen (Tam) at P0-P1 to induce HC death and spontaneous HC regeneration and cochleae were collected at P2, P4, or P6. Representative confocal slice images with anti- $\beta$ gal antibodies to detect Hes5-LacZ expression (green), anti-Sox2 antibodies to label all SC nuclei (magenta), and anti-S100a1 antibodies to label the cytoplasm of PCs/DCs (red). Scale bar $=25 \mu \mathrm{m}$ (H) In the PCs/DCs region, fewer Sox2-positive cells were detected at P4 and P6 after HC damage, while a decreased number of Hes5-LacZ-positive cells were detected at all three ages. Only at P2 were there significantly more Sox2-positive/Hes5-LacZ-negative cells detected. (I) There was no significant change in the number of Sox2-positive, Hes5-LacZ-positive, or Sox2-positive/Hes5-LacZ-negative cells in the IPhCs/BCs region. ${ }^{* *} p<0.01,{ }^{* * *} p<0.001,{ }^{* * * *} p<0.0001$ as determined by a two-way ANOVA with a Tukey's or Sidak's post hoc test. $N=4-5$. 


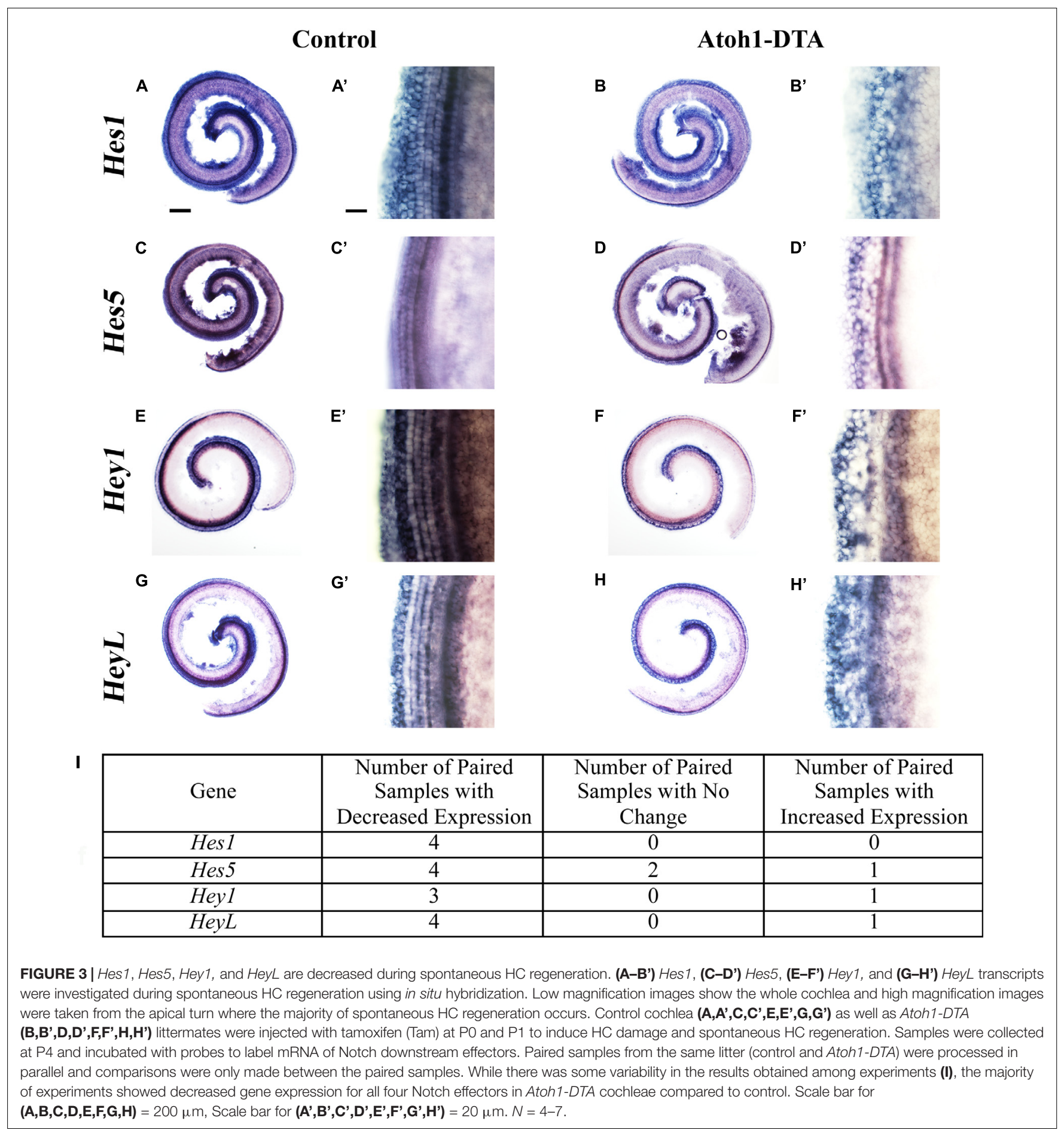

region (low magnification images in Figures $\mathbf{3 A}, \mathbf{B}, \mathbf{C}, \mathbf{D}, \mathbf{E}, \mathbf{F}, \mathbf{G}, \mathbf{H}$ ) and at the $\mathrm{HC}$ level (high magnification images taken in the apical turn, Figures $\mathbf{3} \mathbf{A}^{\prime}, \mathbf{B}, \mathbf{C}^{\prime}, \mathbf{D}^{\prime}, \mathbf{E}, \mathbf{F}^{\prime}, \mathbf{G}^{\prime}, \mathbf{H}^{\prime}$ ) was compared between the paired control and experimental samples to determine increased or decreased expression. Expression of Hes1 was consistently decreased in Atoh1-DTA samples compared to controls (Figure 3A-B',I, $N=4$ ), while variable results were obtained for the other tested genes. For Hes5, four out of seven samples showed decreased expression, while one showed increased expression and two showed no change in expression (Figures 3C-D',I). Hey1 expression was also variable with three samples showing decreased expression and one sample showing increased expression (Figures 3E-F,II). For HeyL, four samples showed decreased expression, while one showed increased expression (Figures 3G-H', I). SC-to-HC conversion is a dynamic and non-synchronous process that occurs throughout the first 
postnatal week (Cox et al., 2014); the variability of individual gene changes we observed may depend on the stage of SC conversion into HCs at the time of analysis. Nevertheless, because the majority of the samples showed decreased expression of Notch effectors, we conclude that loss of HCs in the neonatal mouse cochlea caused a modest decrease in Notch signaling in neighboring SCs.

\section{The Notch Ligand and Target Gene Jag1 Is Reduced During Spontaneous HC Regeneration}

The Notch ligand Jag1 is expressed by neonatal SCs and is also a downstream target of Notch activation (Daudet and Lewis, 2005; Murata et al., 2009). Therefore, it can be used as an indicator of active Notch signaling. Early in development Jag1 mediates lateral induction, establishing the progenitor pool from which all HCs and SCs differentiate (Brooker et al., 2006; Kiernan et al., 2006; Murata et al., 2009). However, its function during and after $\mathrm{HC}$ differentiation is not well understood, yet it is expressed throughout the organ of Corti from the cells of the GER to the 3rd row of Deiters' cells (Figures 4A-C,G-I,M-O; Oesterle et al., 2008). We investigated changes in Jag1 in the context of $\mathrm{HC}$ loss and spontaneous $\mathrm{HC}$ regeneration as an additional way to assess changes in the Notch signaling pathway. Specifically, Atoh1-DTA mice were injected with tamoxifen (3 mg/40 g, IP) at $\mathrm{P} 0$ and $\mathrm{P} 1$ to induce $\mathrm{HC}$ ablation thus initiating spontaneous $\mathrm{HC}$ regeneration. Samples were collected at P2, P4, and P6 and immunolabeled with antibodies against S100a1 and Jag1. Because Jag1 is a membrane bound protein, we could not determine which neighboring cells expressed Jag1 and therefore quantitative analysis was not performed. However, qualitative analysis of Atoh1-DTA cochleae showed that Jag1 labeling was reduced in the lateral region of the organ of Corti, where outer pillar cells and Deiters' cells are located, yet maintained in medial SCs, including inner pillar cells, inner phalangeal/border cells, and the cells of the GER (Figures 4D-F,J-L,P-R). In contrast, Jag1 labeling was consistent in all SCs throughout the width of organ of Corti in control mice (Figures $\mathbf{4 A - C , G - I , M - O ) . ~ T h e s e ~ d a t a ~}$ confirm the results obtained using the Hes $5^{\text {LacZ }}$ reporter mice and demonstrate that Notch signaling is reduced in some SC subtypes, but not others, during spontaneous HC regeneration.

\section{Overexpression of N1ICD Caused Increased Notch Activity in the Neonatal Cochlea}

While immunostaining and in situ hybridization results suggest a modest decrease in Notch signaling during spontaneous HC regeneration, it is currently unknown whether Notch signaling is involved in the mechanism of spontaneous $\mathrm{HC}$ regeneration or if it is simply correlated. To investigate this question more directly, we induced overexpression of N1ICD in SCs and other nonsensory epithelial cells (all other cells within the organ of Corti except for HCs and tympanic border cells, hereinafter referred to as non-HCs) in the context of $\mathrm{HC}$ damage and quantified the number of regenerated HCs using fate-mapping. This was achieved by combining CreER/loxP and Tet-on genetically modified mouse systems to modify gene expression in adjacent cell populations.

To ensure feasibility of using these two inducible systems in adjacent groups of cells without cross-reaction, dual reporter expression was investigated in Atoh1-

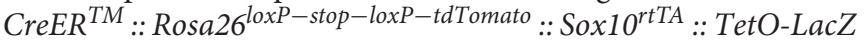
mice. tdTomato expression was induced with tamoxifen injection ( $3 \mathrm{mg} / 40 \mathrm{~g}$, IP) at P0 and P1, while LacZ expression was induced by administering doxycycline to the nursing mother in the food $(2000 \mathrm{mg} / \mathrm{kg})$ from P0-P7, as well as a single injection $(100 \mathrm{mg} / \mathrm{kg})$ to each pup at P1. Samples were analyzed at P7. As expected, tdTomato expression was only detected in HCs, while LacZ expression was observed in SCs and non-HCs (Figures $\mathbf{5 A - G}$ ). We also observed variability in the intensity of LacZ expression cell to cell, which was similar to the previously described pattern using the same doxycycline

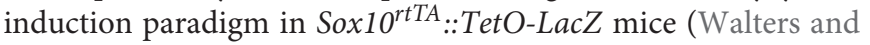
Zuo, 2015).

To investigate whether downregulation of Notch signaling plays a role in spontaneous $\mathrm{HC}$ regeneration, we used Sox10 $10^{\text {rtA }:: T e t O-L a c Z:: T e t O-N 1 I C D}$ mice to overexpress N1ICD as well as $L a c Z$ to fate-map cells. Therefore, in this mouse model, Sox $10^{r t T A}$ must activate two Tet-on alleles simultaneously. To verify that active Notch signaling was achieved in our model and that the presence of the TetO-LacZ allele did not affect the level of Notch activation, we measured N1ICD expression levels using qPCR. Specifically, Sox $10^{r t T A}$-negative, Sox10 $10^{r t T}::$ TetO-N1ICD,

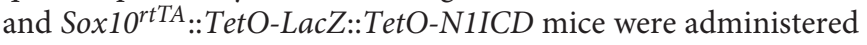
doxycycline, both in the diet to the nursing mother $(2000 \mathrm{mg} / \mathrm{kg})$, as well as a single injection to the pups (100 mg/kg, IP) at P1. RNA was extracted from samples collected at P7 and N1ICD expression was analyzed with qPCR. Of note, the primers used for N1ICD detection recognize both the endogenous and transgenic transcripts and data is expressed as fold change relative to the Sox $10^{r t T A}$-negative control. In both Sox10 ${ }^{\text {rtTA }:: T e t O-}$ N1ICD and Sox10 rtTA ::TetO-LacZ::TetO-N1ICD groups, N1ICD was increased 5 to 6 -fold $\left(6.4 \pm 0.9\right.$-fold for Sox $10^{\text {rtTA }:: T e t O-}$ N1ICD, $p<0.001, N=10$ and $5.7 \pm 0.8$-fold for Sox10 ${ }^{r t T A}::$ TetOLacZ::TetO-N1ICD, $p<0.001, N=10$ compared to Sox $10^{r t T A}$ negative samples; as determined by a one-way ANOVA with a Tukey's post hoc test, Figure 6A). There was no difference in the expression level of N1ICD between Sox10 rtTA ::TetO-N1ICD and Sox $10^{r t T A}::$ TetO-LacZ::TetO-N1ICD samples, indicating that the addition of the TetO-LacZ allele did not interfere with increased Notch activity induced by the TetO-N1ICD allele.

To further confirm increased Notch activity in our model, we used qPCR to investigate the expression level of Notch target genes, Hes1, Hes5, Hey1, and HeyL. All Notch effector genes were increased 2 to 13 -fold in Sox10 ${ }^{\text {rtTA }:: T e t O-L a c Z:: T e t O-}$ N1ICD cochleae compared to Sox $10^{r t T A}$-negative controls (Hes1 increased $2.6 \pm 0.1$-fold, $p<0.0001, N=10$; Hes5 increased $12.7 \pm 1.2$-fold, $p<0.0001, N=10$; Hey1 increased $2.4 \pm 0.2$ fold, $p<0.0001, N=10$; and HeyL increased $7.5 \pm 0.7$-fold, $p<0.0001, N=10$ compared to Sox $10^{r t T A}$-negative controls as determined by a Student's $t$-test for each gene; Figure 6B). Therefore, we conclude that Notch signaling was increased by N1ICD overexpression in our model. 


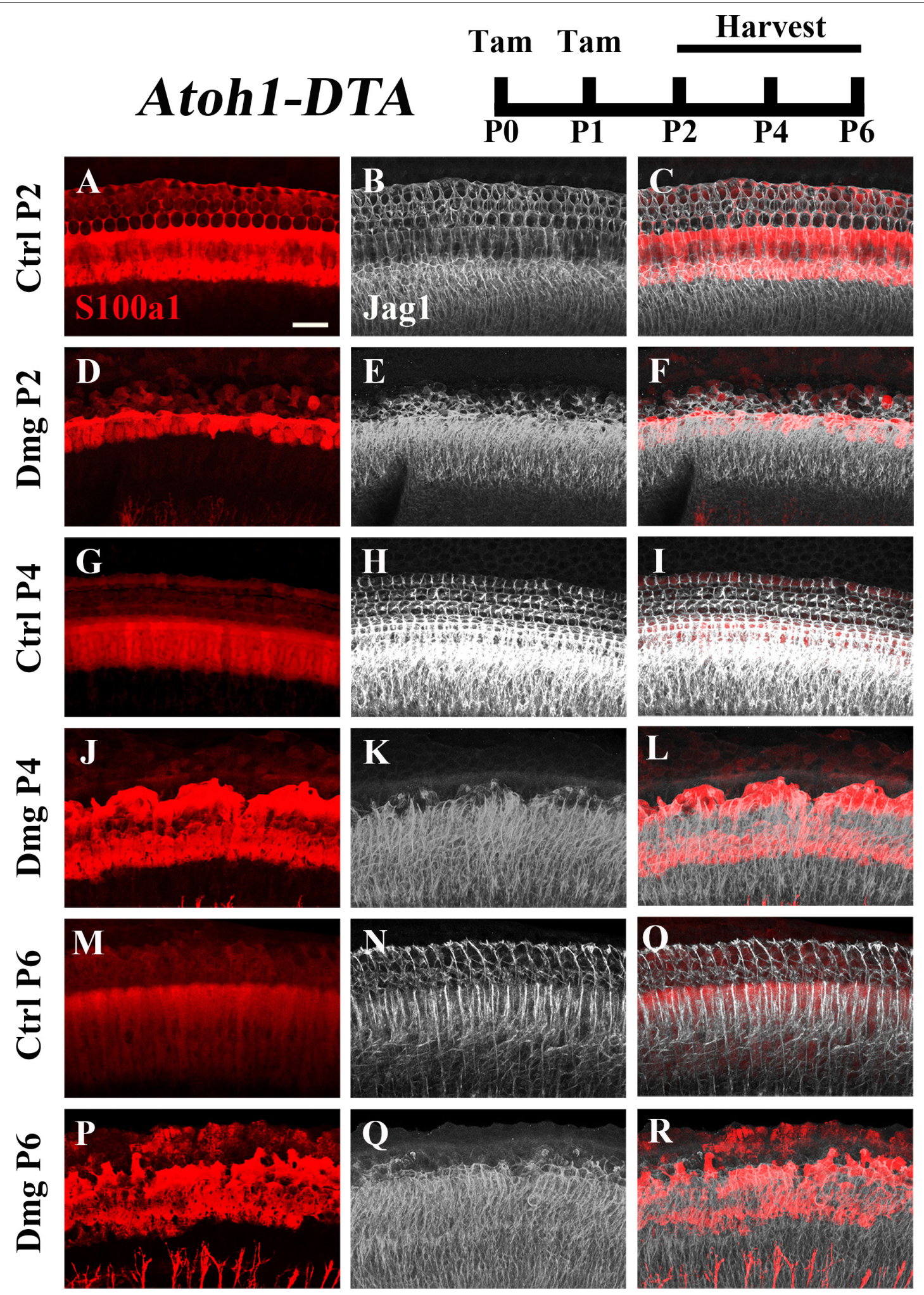

FIGURE 4 | Jag1 labeling is reduced in lateral, but not medial, SCs during spontaneous HC regeneration. Atoh1-DTA mice were injected with tamoxifen (Tam) at P0-P1 to induce HC death and spontaneous HC regeneration and cochleae were collected at P2, P4, or P6. (A,R) Representative maximum projection images with anti-Jag1 antibodies to detect Jag1 expression (white) and anti-S100a1 (red) antibodies to mark the pillar and Deiters' cells region. After HC damage, both S100a1 and Jag1 labeling was reduced in the outer pillar and Deiters' cell region, while expression is maintained in medial SCs (D-F,J-L,P-R) and in all SCs in control samples (A-C, G-I,M-O). Scale bar $=25 \mu \mathrm{m} . N=3$. 


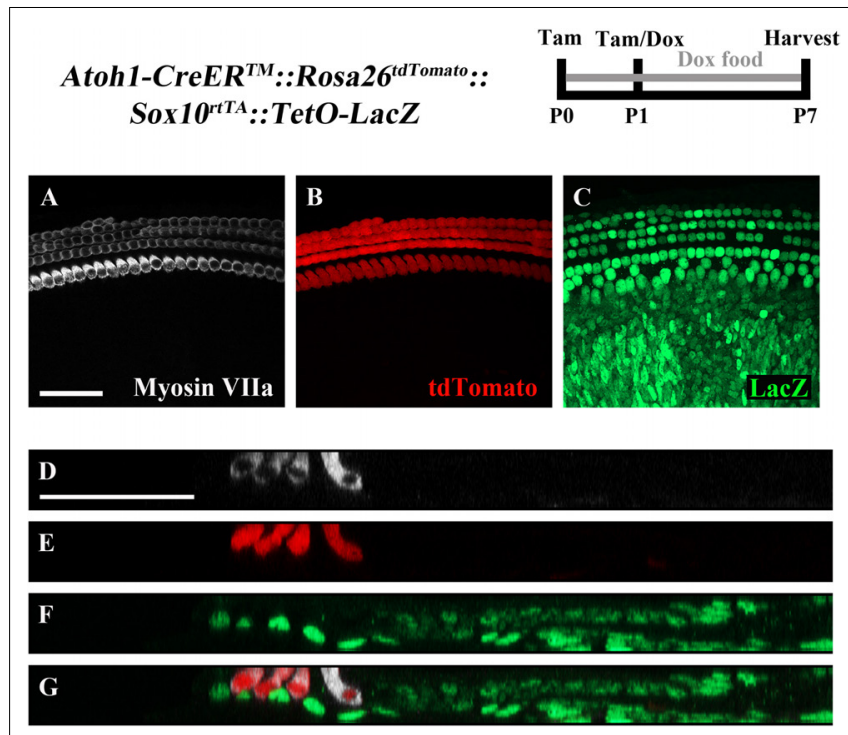

FIGURE 5 | The combination of CreER/loxP and Tet-On genetic systems allow gene manipulation in distinct cell types without cross-reactivity.

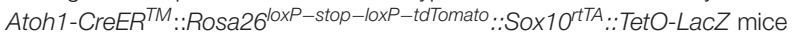
were injected with tamoxifen (Tam) at P0 and P1 to induce tdTomato expression. Doxycycline (Dox) was administered to nursing mother in the diet and each pup received a dox injection at P1 to induce LacZ expression. Cochleae were collected at P7 and stained with antibodies against myosin VIla (white) to label HCs and $\beta$-gal (green) to label LacZ-positive cells. (A-C) Representative confocal slice images show expression of endogenous tdTomato fluorescence (red) detected in HCs similar to Cox et al. (2014). $\beta$-gal expression (green) was detected in SCs and other non-HCs similar to Walters and Zuo (2015). (D-G) Optical cross-sections showing expression of tdTomato in HCs and $\beta$-gal in SCs and all non-HCs. Scale bar $=50 \mu \mathrm{m} . N=3$.

\section{Spontaneous HC Regeneration Is Reduced When the N1ICD Is Overexpressed in SCs and Other Non-HCs}

To investigate whether spontaneous HC regeneration could be prevented by increased Notch signaling, we overexpressed NIICD in SCs and other non-HCs in the context of HC damage using Atoh1-DTA::Sox10 rtTA ::TetO-LacZ::TetO-N1ICD mice. The effect of increased Notch signaling on spontaneous $\mathrm{HC}$ regeneration was investigated by quantifying the number of fate-mapped SCs. Specifically, we analyzed the number of LacZ-positive HCs in each of four groups. First, to verify the expression pattern of Sox $10^{r t T A}$ in a normal neonatal cochlea, the number of LacZ-positive HCs was quantified in Sox10 ${ }^{r t T A}:$ :TetO-LacZ mice. Second, to determine the number of spontaneously regenerated HCs that occur naturally in the neonatal mouse cochlea after HC loss at birth, we quantified LacZ-positive HCs in Atoh1-DTA::Sox10 ${ }^{r t T A}::$ TetO-LacZ mice. Third, to determine the effect of N1ICD overexpression in SCs and other non-HCs in the neonatal mouse cochlea, LacZpositive HCs were quantified in Sox10 ${ }^{r t T A}::$ TetO-LacZ::TetONIICD mice. Finally, to investigate whether overexpression of NIICD in SCs and other non-HCs will prevent spontaneous HC regeneration from occurring, we quantified LacZ-positive HCs
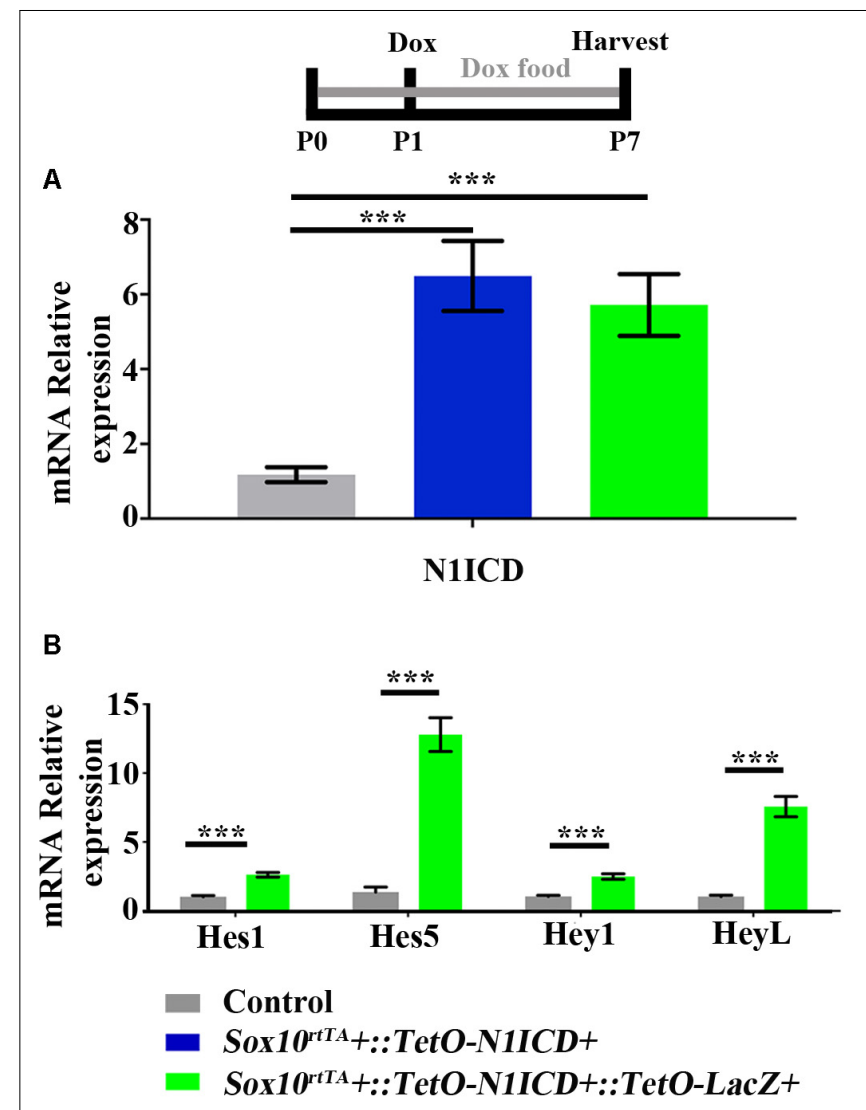

FIGURE 6 | Increased expression of N1/CD driven by Sox10'tTA leads to increased expression of Notch downstream effectors. Sox $10^{r t T A}$-negative, Sox10 rTA ::TetO-N1ICD, and Sox10 rTA ::TetO-LacZ::TetO-N1ICD mice were administered doxycycline (Dox), in the diet to nursing mother, as well as an injection to each pup at P1. Cochleae were frozen at P7 and mRNA transcripts were measured. (A) N1/CD expression was increased in Sox10 rTA ::TetO-N1ICD, and Sox10 rtTA::TetO-LacZ::TetO-N1/CD cochlea, compared to Sox10rtTA -negative controls. There was no difference in the expression of N1/CD when TetO-LacZ was also present. (B) Expression level of Notch effectors Hes1, Hes5, Hey1, and HeyL were increased in Sox10 rtTA ::TetO-LacZ::TetO-N1ICD cochlea, compared to Sox10 $10^{\text {rTA }}$-negative controls. ${ }^{* * *} p<0.001$ as determined by a one-way ANOVA with a Dunnett's post hoc test or a Student's $t$-test. $N=10$.

in Atoh1-DTA::Sox10 rtTA ::TetO-LacZ::TetO-N1ICD mice. Mice from each group were injected with tamoxifen $(3 \mathrm{mg} / \mathrm{kg}$, IP) at $\mathrm{P} 0$ and P1 to induce HC damage. N1ICD and LacZ expression were induced through administration of doxycycline given both in the food $(2000 \mathrm{mg} / \mathrm{kg})$ to the nursing mother, as well as one doxycycline injection $(100 \mathrm{mg} / \mathrm{kg}$, IP) given to the pups at P1, $\sim 6 \mathrm{~h}$ after tamoxifen injection. Samples were collected at P7 and processed for immunostaining with antibodies against myosin VIIa, Sox 2 , and $\beta$-gal.

As expected from previous work (Walters and Zuo, 2015), LacZ expression in Sox10 ${ }^{\text {rtTA }}:: T e t O-L a c Z$ mice was observed in SCs and other non-HCs within the P7 cochlea. We also observed $2.0 \pm 2.0$ LacZ-positive HCs in the very apical tip (Figures $7 \mathbf{Q}, \mathbf{R}$, $N=4$ ). There was no significant change in LacZ-positive HCs when NIICD was overexpressed without HC damage in 


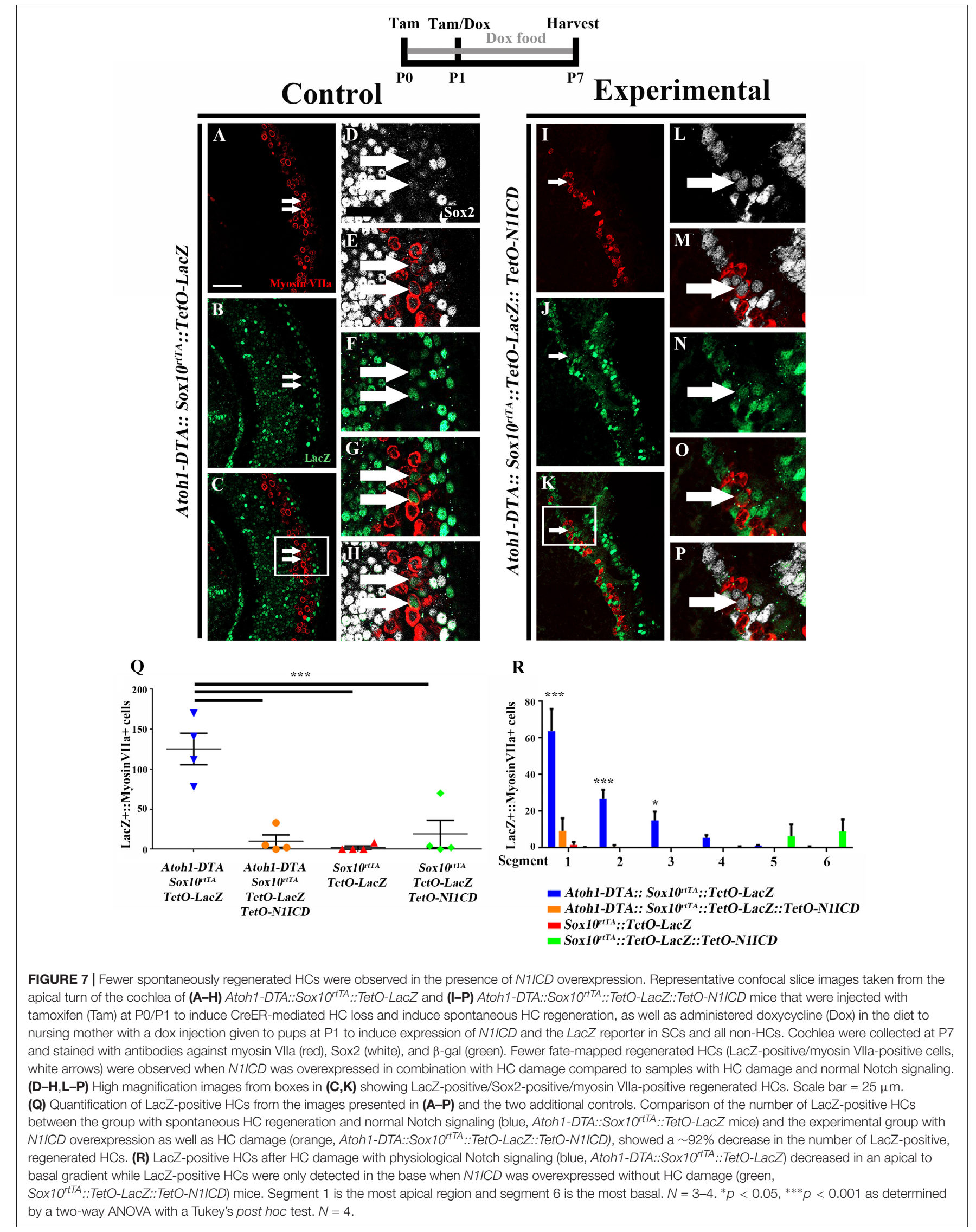




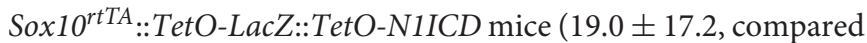
to Sox $10^{r t T A}::$ TetO-LacZ controls, $N=4, p=0.8$ as determined by a one-way ANOVA with a Tukey's post hoc test; Figure 7Q). However, we observed disorganization of HCs (Supplementary Figures S2A,G) as well as an expansion of Sox2 expression both medial and lateral to the organ of Corti, (Supplementary Figures S2A-D,F-I). Quantification of HCs in Sox10 ${ }^{\text {rtTA }:: T e t O-}$ LacZ::TetO-N1ICD mice showed that there was no difference in the number of HCs compared to Sox $10^{r t T A}::$ TetO-LacZ mice (91.0 \pm 2.5 compared to $88.7 \pm 5.9$ per $200 \mu \mathrm{m}, p=0.5$ as determined by a Student's $t$-test, Supplementary Figure S2E) and therefore this phenotype likely did not affect spontaneous HC regeneration observed in our study.

When LacZ was used for fate-mapping during spontaneous $\mathrm{HC}$ regeneration, significantly more LacZ-positive HCs were detected in Atoh1-DTA::Sox10 ${ }^{\text {rtTA }:: T e t O-L a c Z ~ m i c e ~ t h a n ~ i n ~}$ Sox10 ${ }^{\text {rtTA }:: T e t O-L a C Z}$ controls (125.3 \pm 19.7 compared to $2.0 \pm 2.0, p=0.0002, N=4$, Figure 7Q). When N1ICD was overexpressed in the context of HC damage (Atoh1DTA::Sox $10^{\text {rtTA }:: T e t O-L a c Z:: T e t O-N 1 I C D}$ mice), there was a $92 \%$ reduction in LacZ-positive $\mathrm{HCs}$ compared to similar samples without N1ICD overexpression (Atoh1-DTA::Sox10 rtTA::TetO$\mathrm{LacZ}$ mice) (10.0 \pm 7.7 compared to $125.3 \pm 19.7, p=0.0003$, $N=4$, Figures 7A-Q). Moreover, the number of LacZpositive HCs when N1ICD was overexpressed and HCs were killed was not significantly different from controls lacking both HC damage and N1ICD overexpression (Sox10 ${ }^{\text {rtTA }:: T e t O-}$ LacZ samples) $(10.0 \pm 7.7$ compared to $2.0 \pm 2.0, p=0.9)$ or N1ICD overexpression alone (Sox10rtTA::TetO-LacZ::TetON1ICD samples) $(10.0 \pm 7.7$ compared to $19.0 \pm 17.0, p=0.9$ as determined by a one-way ANOVA with a Tukey's post hoc test; Figure 7Q). Therefore, we conclude that overexpression of N1ICD prevented the majority of spontaneous HC regeneration from occurring. Of note, we observed an expansion of Sox2 expressing cells in Atoh1-DTA::Sox10 $0^{\text {rtTA }:: T e t O-L a c Z:: T e t O-}$ N1ICD mice, similar to what we observed in Sox10 ${ }^{\text {rtTA }:: T e t O-}$ LacZ::TetO-N1ICD controls (Supplementary Figures S2F-M).

We wanted to better understand the location of fate-mapped, spontaneously regenerated $\mathrm{HCs}$ in our samples because the majority of spontaneous $\mathrm{HC}$ regeneration is known to occur in the apical third of the neonatal cochlea (Cox et al., 2014) and because Notch signaling decreases in a basal to apical gradient during the first postnatal week (Maass et al., 2015). Therefore, the whole cochlea was imaged, measured, and divided into six equal segments from apex to base as previously described (McGovern et al., 2017) and the total number of LacZ-positive/myosin VIIapositive HCs within each segment was quantified. The majority of fate-mapped, spontaneously regenerated HCs (from Atoh1-

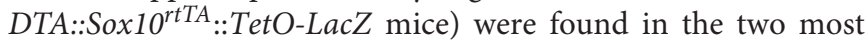
apical segments $(63.8 \pm 12.0$ in segment 1 and $26.8 \pm 4.9$ in segment 2) and this declined in an apical to basal gradient $(15.4 \pm 4.8$ in segment $3,5.6 \pm 1.4$ in segment $4,1.2 \pm 0.3$ in segment 5 , and $0.4 \pm 0.4$ in segment $6, r^{2}=0.66 . p<0.0001$ Figure 7R), similar to the previous report (Cox et al., 2014). In one Sox $10^{\text {rtTA }:: T e t O-L a c Z:: T e t O-N 1 I C D}$ sample that did not have HC damage, we observed 67 LacZ-positive HCs in the two basal segments, but no LacZ-positive HCs were detected in the middle or apical segments of the cochlea where the majority of HC regeneration was observed (Figure 7R). The other three Sox10 rtTA ::TetO-LacZ::TetO-N1ICD samples had no LacZ-positive HCs. Therefore, the LacZ-positive HCs observed in N1ICD overexpressing controls did not interfere with the quantification of fate-mapped, spontaneously regenerated HCs predominantly observed in the apical turn of the cochlea. When N1ICD was overexpressed along with HC damage, the fatemapped regenerated HCs in the Atoh1-DTA::Sox10 rtTA ::TetOLacZ::TetO-N1ICD mice were all located within the first two apical segments (Figure $7 \mathbf{R}$ ), similar to the control with spontaneous $\mathrm{HC}$ regeneration and no manipulation of Notch (Atoh1-DTA::Sox10 rtTA::TetO-LacZ mice). This illustrates that the regenerative capacity of SCs is correlated to the basal to apical changes in the Notch signaling pathway. Our data show weakened Notch signaling during the spontaneous $\mathrm{HC}$ regeneration process, as well as the suppression of $\mathrm{HC}$ regeneration by increased Notch activity. Taken together, this suggests that Notch signaling plays a role in the ability of SCs to spontaneously convert into, thus regenerate, HCs.

\section{DISCUSSION}

This study investigated the role of Notch signaling during spontaneous HC regeneration within the neonatal mouse cochlea in vivo. After $\mathrm{HC}$ damage and during the window of spontaneous HC regeneration, we observed a modest decrease in Notch signaling, as evidenced by decreased expression of the Notch target genes Hes1, Hes5, Hey1, HeyL, and Jag1 using immunostaining or in situ hybridization. These changes suggest that Notch signaling is weakened in SCs after HC loss occurs and may allow their conversion into HCs. To investigate this further, we increased Notch signaling in SCs and other non-HCs by overexpressing N1ICD during the window of spontaneous HC regeneration. In samples with increased Notch signaling, there was a $92 \%$ reduction in the number of spontaneously regenerated HCs, suggesting that Notch signaling plays a role in spontaneous $\mathrm{HC}$ regeneration.

\section{The Expression of Hes1, Hes5, Hey1, and HeyL Were Reduced During the Window of Spontaneous HC Regeneration}

Using in situ hybridization and a Hes $5^{\text {LacZ }}$ knockin reporter line, we discovered that the expression of Hes1, Hes5, Hey1, and HeyL was reduced after $\mathrm{HC}$ loss and during the spontaneous $\mathrm{HC}$ regeneration process. Both Hes 1 and Hes 5 directly inhibit a HC fate by inhibiting the expression of Atoh1, a transcription factor that is necessary for HC differentiation (Zheng et al., 2000; Mulvaney and Dabdoub, 2012; Abdolazimi et al., 2016). Previously, Korrapati et al. (2013) found that HC damage after gentamicin treatment in vitro leads to downregulation of Hes5, but no other Notch-related genes expressed in SCs. However, no $\mathrm{HC}$ regeneration was observed in this model until Notch signaling was inhibited with a $\gamma$-secretase inhibitor, which caused decreased expression of all Notch downstream effectors. This suggests that reduction of Hes5 signaling alone 
is insufficient to induce spontaneous $\mathrm{HC}$ regeneration, however, when reduced expression is expanded to additional Notch effectors, regeneration is possible. In support, overexpression of Hes 1 is able to inhibit the production of ectopic HCs in the GER that were created by ectopic expression of Atoh1. This indicates that Hes 1 is also a direct inhibitor of HC fate (Zheng et al., 2000). Furthermore, combined loss of Hes1, Hes5, and Heyl during late embryonic development [embryonic day (E) 18.5] caused increased outer HCs with disorganized pillar and Deiters' cells (Tateya et al., 2011). Unfortunately, less is known about the function of the Notch effector HeyL in cochlear development, however, it is expressed around the time of $\mathrm{HC}$ differentiation and is linked to neuronal differentiation in other systems (Doetzlhofer et al., 2009; Jalali et al., 2011). Therefore, combined reduction of Hes1, Hes5, and Hey1, and possibly HeyL, observed in our study are correlated with the ability of SCs to spontaneously regenerate HCs in the neonatal mouse cochlea, thus supporting our conclusion that weakened Notch signaling allows SC-to-HC conversion and plays a role in spontaneous HC regeneration.

\section{Jag1 Is Reduced During the Spontaneous HC Regeneration Process}

In the developing cochlea, Jag1 is initially expressed throughout the sensory epithelium, then restricted to SCs, with expression in all SC subtypes from the GER to the 3rd row of Deiters' cells at neonatal ages and in adulthood (Morrison et al., 1999; Daudet and Lewis, 2005; Oesterle et al., 2008; Murata et al., 2009). However, its function during and after HC differentiation is not well understood. Furthermore, Jag1 is both a Notch ligand as well as a Notch target gene (Daudet and Lewis, 2005; Murata et al., 2006) and as such, reduced expression of this gene can indicate loss of Notch signaling. Consistent with results from the Hes $5^{\text {LacZ }}$ reporter and in situ hybridization, Jag1 expression was decreased in Atoh1-DTA samples in outer pillar and Deiters' cells, the SC subtypes located underneath outer HCs in the lateral compartment of the cochlea. This finding further supports our conclusion that there is a modest decrease in Notch activity in SCs after $\mathrm{HC}$ damage and during $\mathrm{HC}$ regeneration in the neonatal cochlea.

\section{The Majority of Spontaneous HC Regeneration Is Prevented When N1ICD Is Overexpressed in SCs and Other Non-HCs in the Neonatal Mouse Cochlea}

Previous work has focused on the effect of induced Notch inhibition via pharmacologic manipulation with $\gamma$-secretase inhibitors (Yamamoto et al., 2006; Korrapati et al., 2013; Li et al., 2015) or deletion of Notch receptors or RBP-J (Yamamoto et al., 2006; Bramhall et al., 2014; Li et al., 2015). From these studies we know that loss of Notch signaling triggers SC-to-HC conversion, however, while this approach produces new HCs, it applies a blanket reduction in all Notch related genes, as well as potentially affects other signaling pathways that $\gamma$-secretase interacts with such as ErbB-4, E-Cadherin, N-Cadherin, EphrinB, and CD44 (Ni et al., 2001; Lammich et al., 2002; Marambaud et al., 2002, 2003; Georgakopoulos et al., 2006). Therefore, it is unclear whether decreased Notch signaling in SCs is part of the molecular mechanism for spontaneous HC regeneration. Our study attempts to address this gap in knowledge by showing that overexpression of N1ICD in SCs and other non-HCs causes an increase in Notch signaling and results in a $92 \%$ reduction in the number of regenerated HCs. However, the mouse model we used generated supraphysiological levels of Notch activity with N1ICD increased 5 to 6-fold and Hes/Hey genes increased 2 to 13 -fold over controls. It is possible that the level of Notch signaling is important in controlling $\mathrm{HC}$ and SC fate. In support of this notion, there was one Atoh1DTA::Sox $10^{r t T A}::$ TetO-LacZ::TetO-N1ICD sample with 33 fatemapped regenerated $\mathrm{HCs}$, while the other three samples that had 0-5 fate-mapped regenerated HCs. While not directly tested, the sample with more regenerated HCs may have had lower expression of NIICD compared to the other three samples, which could have been caused by decreased exposure to doxycycline. Despite the limitation of supraphysiological NIICD and Notch effector levels in our model, data from this study support a role for Notch signaling during the spontaneous HC regeneration process.

Sox $10^{r t T A}$ is a knockin allele that may produce decreased expression of Sox 10 in the neonatal cochlea. It is possible that decreased Sox10 expression may alter normal spontaneous HC regeneration making it more dependent on Notch signaling and therefore making N1ICD overexpression more effective at preventing regeneration. While we cannot rule out this possibility, a previous study showed that Sox $10^{r t T A}$ mice do not have a haploinsufficient phenotype in the cochlea (Walters and Zuo, 2015). Yet little is known about the relationship between Sox10 and Notch signaling, and further research is needed.

Unexpectedly, in the control samples where N1ICD was overexpressed without HC damage (Sox10 rtTA ::TetOLacZ::TetO-N1ICD mice) and in experimental samples (Atoh1-DTA::Sox10 rtTA ::TetO-LacZ::TetO-N1ICD mice), we observed an expansion of the region with Sox2-positive cells both medial and lateral to the organ of Corti. Sox10 $10^{\text {rtTA }:: T e t O-}$ LacZ::TetO-N1ICD controls also had disorganized HCs, but no decrease in HC number. Similar studies were done previously in the embryonic and early neonatal cochlea where NIICD overexpression led to ectopic sensory patches containing both Sox2-positive cells and HCs in non-sensory regions. Yet this was only observed when N1ICD was overexpressed prior to E14.5 (Hartman et al., 2010; Pan et al., 2010, 2013; Liu et al., 2012; Campbell et al., 2015). Studies where N1ICD overexpression was induced after E14.5 showed no ectopic HCs or Sox2-positive cells (Liu et al., 2012; Pan et al., 2013). These studies demonstrate that N1ICD overexpression can induce Sox 2 expression and sensory progenitor cells in non-sensory regions, yet there is a temporal limitation for when these cells can respond. Therefore, the increased numbers of Sox2-positive cells we observed when N1ICD was overexpressed at P0 was unexpected. We may have overcome temporal limitations by producing supraphysiological levels of NIICD and Notch effectors, but further experiments are needed to confirm this hypothesis. Regardless of the cause, we do 
not believe expanded Sox2 expression altered the spontaneous $\mathrm{HC}$ regeneration process or affected the conclusions of our study since all abnormalities, except $\mathrm{HC}$ disorganization, were observed outside the organ of Corti.

Notch signaling changes dynamically in the first week after birth where ligands, receptors, and effectors are downregulated in a basal-to-apical gradient between P0 and P6 (Murata et al., 2006; Hartman et al., 2007; Maass et al., 2015). However, Jag1 is the exception and its expression in SCs continues throughout adulthood (Oesterle et al., 2008). During the first postnatal week, inhibition of Notch signaling using $\gamma$-secretase inhibitors has differential effects on SC-to-HC conversion along the basal to apical axis. Notch inhibition at P0 produces a $\sim 200 \%$ increase in HCs in the apex compared to only a $\sim 30 \%$ increase in the base, while there is no evidence of $\mathrm{HC}$ production in any cochlear turn when $\gamma$-secretase inhibitors are used at $\mathrm{P} 3$ or later (Maass et al., 2015). There are conflicting reports for whether SCs can produce HCs in response to Notch inhibition in the adult cochlea (Batts et al., 2009; Doetzlhofer et al., 2009; Hartman et al., 2009; Mizutari et al., 2013). These data taken together with our results suggest that spontaneous $\mathrm{HC}$ regeneration likely occurs when HCs are killed at P0-P1 because SCs, especially those in the apical turn, are still dependent on Notch signaling to maintain their cell fate. As the cochlea matures, it appears that SC fate maintenance becomes uncoupled from Notch signaling, yet the upstream regulators or epigenetic changes that cause downregulation of the Notch pathway, as well as the mechanisms that maintain SC fate after the first postnatal week are unknown.

Nevertheless, while previous studies have shown that increased numbers of regenerated HCs can form when Notch signaling is inhibited (Korrapati et al., 2013; Bramhall et al., 2014; Hu et al., 2016), the findings presented here are the first to demonstrate that the spontaneous HC regeneration process is prevented by increased Notch signaling. This suggests that weakened Notch signaling plays a role in the spontaneous HC regeneration process. Understanding the molecular mechanism of spontaneous $\mathrm{HC}$ regeneration is a critical step to understanding why $\mathrm{HC}$ regeneration does not occur in the mature cochlea. Additionally, while some Notch effectors, such as Hes 1 and Hes5, are well established as inhibitors of $\mathrm{HC}$ fate, less is known about the contribution of other effectors on SC-to-HC conversion. The findings presented here will hopefully drive research to identify cellular and molecular changes that occur within the first postnatal week to uncouple Notch signaling and SC fate maintenance. Understanding what assumes control over SC fate in the adult cochlea will potentially lead investigations into therapeutic targets to stimulate $\mathrm{HC}$ regeneration in the mature cochlea.

\section{AUTHOR CONTRIBUTIONS}

MM designed and performed the experiments, analyzed the data, and wrote the manuscript. LZ and MR performed the experiments, analyzed the data, and contributed to writing the manuscript. BC designed the experiments, analyzed the data, and wrote the manuscript.

\section{FUNDING}

This work was supported by the Office of the Assistant Secretary of Defense for Health Affairs (W81XWH-15-10475), the Office of Naval Research (N00014-13-1-0569), and the National Institutes of Health (R01 DC014441). The SIUSOM Research Imaging Facility is supported by a grant from the Office of Naval Research (N00014-15-12866) and the National Center for Research Resources-Health (S10RR027716).

\section{ACKNOWLEDGMENTS}

We thank Kaley Graves from Southern Illinois University School of Medicine for technical assistance, Dr. Bernd Fritzsch from the University of Iowa, and Dr. Andy Wilber from Southern Illinois University School of Medicine for their assistance with in situ hybridization experiments. We thank Dr. Andy Groves from Baylor College of Medicine for the critical discussion and assistance with in situ hybridization experiments. We are grateful to Dr. Suzanne Baker (St. Jude Children's Research Hospital) for sharing Atoh1-CreER $R^{T M}$ mice, Dr. Ryoichiro Kageyama (Kyoto University) for sharing Hes $5^{\text {LacZ }}$ mice, Dr. Michael Wegner (Erlangen University) for sharing Sox $10^{r t T A}$ mice, and Dr. Ben Stranger (University of Pennsylvania) for sharing TetO-N1ICD mice.

\section{SUPPLEMENTARY MATERIAL}

The Supplementary Material for this article can be found online at: https://www.frontiersin.org/articles/10.3389/fncel. 2018.00120/full\#supplementary-material

FIGURE S1 | Inner phalangeal and border cells labeling by Plp-CreER ${ }^{T 2}::$ Rosa26 $6^{\text {tdTomato }}$ (A-C) Representative confocal images of Plp-CreER ${ }^{T 2}::$ Rosa26 tdTomato samples injected with tamoxifen (Tam) at PO. tdTomato labeling allowed the measurement of the inner phalangeal and border cell region for quantification of Hes5-LacZ and Sox2 expressing cells in Figure 2. This width was $9.6 \mu \mathrm{m}$ at P2, $13.2 \mu \mathrm{m}$ at P4, and $16.8 \mu \mathrm{m}$ at P6. Scale bar $=25 \mu \mathrm{m}$.

FIGURE S2 | Expansion of the Sox2-postive region and HC disorganization when N1/CD is overexpressed. (A-D) Representative confocal images taken from the apical turn of the cochlea from Sox10 rtTA ::TetO-LacZ::TetO-N1/CD mice that were injected with tamoxifen (Tam) at P0/P1 as well as administered doxycycline (Dox) in the diet to nursing mother with a doxycycline injection given to pups at $P 1$ to induce expression of N1/CD and the LacZ reporter in SCs and other non-HCs. Cochlea were collected at P7 and stained with antibodies against myosin VIla (red), Sox2 (white), and $\beta$-gal (green). While there was disorganization of HCs (A), there was no change in the number of HCs in any of the cochlear turns. (E, quantified in a $200 \mu \mathrm{m}$ region). Scale bar $=25 \mu \mathrm{m} . N=4$. (F-I) Maximum

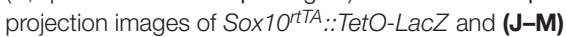

Atoh1-DTA::Sox10 rtTA ::TetO-LacZ::TetO-N1/CD apical turns showing expanded Sox2 expression medial and lateral to the organ of Corti. Scale bar $=20 \mu \mathrm{m}$. 


\section{REFERENCES}

Abdolazimi, Y., Stojanova, Z., and Segil, N. (2016). Selection of cell fate in the organ of Corti involves the integration of Hes/Hey signaling at the Atoh1 promoter. Development 143, 841-850. doi: 10.1242/dev.129320

Basch, M. L., Ohyama, T., Segil, N., and Groves, A. K. (2011). Canonical Notch signaling is not necessary for prosensory induction in the mouse cochlea: insights from a conditional mutant of RBPj. J. Neurosci. 31, 8046-8058. doi: 10.1523/JNEUROSCI.6671-10.2011

Batts, S. A., Shoemaker, C. R., and Raphael, Y. (2009). Notch signaling and Hes labeling in the normal and drug-damaged organ of Corti. Hear. Res. 249, 15-22. doi: $10.1016 /$ j.heares.2008.12.008

Bermingham-McDonogh, O., and Rubel, E. W. (2003). Hair cell regeneration: winging our way towards a sound future. Curr. Opin. Neurobiol. 13, 119-126. doi: 10.1016/S0959-4388(03)00018-7

Bohne, B. A. (1976). Safe level for noise exposure? Ann. Otol. Rhinol. Laryngol. 85, 711-724. doi: 10.1177/000348947608500602

Bramhall, N. F., Shi, F., Arnold, K., Hochedlinger, K., and Edge, A. S. (2014). Lgr5-positive supporting cells generate new hair cells in the postnatal cochlea. Stem Cell Reports 2, 311-322. doi: 10.1016/j.stemcr.2014.01.008

Brignull, H. R., Raible, D. W., and Stone, J. S. (2009). Feathers and fins: nonmammalian models for hair cell regeneration. Brain Res. 1277, 12-23. doi: 10.1016/j.brainres.2009.02.028

Brooker, R., Hozumi, K., and Lewis, J. (2006). Notch ligands with contrasting functions: jagged1 and Deltal in the mouse inner ear. Development 133, 1277-1286. doi: 10.1242/dev.02284

Buckiová, D., and Syka, J. (2009). Calbindin and S100 protein expression in the developing inner ear in mice. J. Comp. Neurol. 513, 469-482. doi: 10.1002/cne. 21967

Campbell, D. P., Chrysostomou, E., and Doetzlhofer, A. (2015). Canonical Notch signaling plays an instructive role in auditory supporting cell development. Sci. Rep. 6:19484. doi: 10.1038/srep19484

Chonko, K. T., Jahan, I., Stone, J., Wright, M. C., Fujiyama, T., Hoshino, M., et al. (2013). Atoh1 directs hair cell differentiation and survival in the late embryonic mouse inner ear. Dev. Biol. 381, 401-410. doi: 10.1016/j.ydbio.2013. 06.022

Chow, L. M., Tian, Y., Weber, T., Corbett, M., Zuo, J., and Baker, S. J. (2006). Inducible Cre recombinase activity in mouse cerebellar granule cell precursors and inner ear hair cells. Dev. Dyn. 235, 2991-2998. doi: 10.1002/dvdy. 20948

Cox, B. C., Chai, R., Lenoir, A., Liu, Z., Zhang, L., Nguyen, D.-H., et al. (2014). Spontaneous hair cell regeneration in the neonatal mouse cochlea in vivo. Development 141, 816-829. doi: 10.1242/dev.103036

Cox, B. C., Liu, Z., Lagarde, M. M., and Zuo, J. (2012). Conditional gene expression in the mouse inner ear using cre-loxP. J. Assoc. Res. Otolaryngol. 13, 295-322. doi: $10.1007 /$ s10162-012-0324-5

Daudet, N., and Lewis, J. (2005). Two contrasting roles for Notch activity in chick inner ear development: specification of prosensory patches and lateral inhibition of hair-cell differentiation. Development 132, 541-551. doi: 10.1242/ dev.01589

Doerflinger, N., Macklin, W., and Popko, B. (2003). Inducible site-specific recombination in myelinating cells. Genesis 35, 63-72. doi: 10.1002/gene.10154/ full

Doetzlhofer, A., Basch, M. L., Ohyama, T., Gessler, M., Groves, A. K., and Segil, N. (2009). Hey2 regulation by FGF provides a notch-independent mechanism for maintaining pillar cell fate in the organ of Corti. Dev. Cell 16, 58-69. doi: 10.1016/j.devcel.2008.11.008

Furth, P. A., Onget, L. S., Bögert, H., Grusst, P., Gossen, M., Kistner, A., et al. (1994). Temporal control of gene expression in transgenic mice by a tetracyclineresponsive promoter. Biochemistry 91, 9302-9306. doi: 10.1073/pnas.91.20.9302

Georgakopoulos, A., Litterst, C., Ghersi, E., Baki, L., Xu, C. J., Serban, G., et al. (2006). Metalloproteinase/presenilin1 processing of ephrinB regulates EphB-induced Src phosphorylation and signaling. EMBO J. 25, 1242-1252. doi: 10.1038/sj.emboj.7601031

Gómez-Casati, M. M., Murtie, J., Taylor, B., and Corfas, G. (2010). Cell-specific inducible gene recombination in postnatal inner ear supporting cells and glia. J. Assoc. Res. Otolaryngol. 11, 19-26. doi: 10.1007/s10162-009-0191-x
Hartman, B. H., Basak, O., Nelson, B. R., Taylor, V., Bermingham-Mcdonogh, O., and Reh, T. A. (2009). Hes5 expression in the postnatal and adult mouse inner ear and the drug-damaged cochlea. J. Assoc. Res. Otolaryngol. 10, 321-340. doi: 10.1007/s10162-009-0162-2

Hartman, B. H., Hayashi, T., Nelson, B. R., Bermingham-McDonogh, O., and Reh, T. (2007). Dll3 is expressed in developing hair cells in the mammalian cochlea. Dev. Dyn. 236, 2875-2883. doi: 10.1002/dvdy.21307

Hartman, B. H., Reh, T. A., and Bermingham-McDonogh, O. (2010). Notch signaling specifies prosensory domains via lateral induction in the developing mammalian inner ear. Proc. Natl. Acad. Sci. U.S.A.107, 15792-15797. doi: $10.1073 /$ pnas. 1002827107

Hawkins, J. E., Johnsson, L. G., Stebbins, W. C., Moody, D. B., and Coombs, S. L. (1976). Hearing loss and cochlear pathology in monkeys after noise exposure. Acta Otolaryngol. 81, 337-343. doi: 10.3109/00016487609119971

Hayashi, T., Kokubo, H., Hartman, B. H., Ray, C. A., Reh, T. A., and BerminghamMcDonogh, O. (2008). Hesr1 and Hesr2 may act as early effectors of Notch signaling in the developing cochlea. Dev. Biol. 316, 87-99. doi: 10.1016/j.ydbio. 2008.01.006

Hu, L., Lu, J., Chiang, H., Wu, H., Edge, A. S., and Shi, F. (2016). Diphtheria toxininduced cell death triggers Wnt-dependent hair cell regeneration in neonatal mice. J. Neurosci. 36, 9479-9489. doi: 10.1523/JNEUROSCI.2447-15.2016

Imayoshi, I., Sakamoto, M., Yamaguchi, M., Mori, K., and Kageyama, R. (2010). Essential roles of notch signaling in maintenance of neural stem cells in developing and adult brains. J. Neurosci. 30, 3489-3498. doi: 10.1523/ JNEUROSCI.4987-09.2010

Ivanova, A., Signore, M., Caro, N., Greene, N. D., Copp, A. J., and MartinezBarbera, J. P. (2005). In vivo genetic ablation by Cre-mediated expression of diphtheria toxin fragment A. Genesis 43, 129-135. doi: 10.1002/gene.20162

Jalali, A., Bassuk, A. G., Kan, L., Israsena, N., Mukhopadhyay, A., McGuire, T., et al. (2011). HeyL promotes neuronal differentiation of neural progenitor cells. J. Neurosci. Res. 89, 299-309. doi: 10.1002/jnr.22562

Kiernan, A. E., Cordes, R., Kopan, R., Gossler, A., and Gridley, T. (2005). The Notch ligands DLL1 and JAG2 act synergistically to regulate hair cell development in the mammalian inner ear. Development 132, 4353-4362. doi: 10.1242/dev. 02002

Kiernan, A. E., Xu, J., and Gridley, T. (2006). The notch ligand JAG1 is required for sensory progenitor development in the mammalian inner ear. PLoS Genet. 2:e4. doi: 10.1371/journal.pgen.0020004

Korrapati, S., Roux, I., Glowatzki, E., and Doetzlhofer, A. (2013). Notch signaling limits supporting cell plasticity in the hair cell-damaged early postnatal murine cochlea. PLoS One 8:e73276. doi: 10.1371/journal.pone.0073276

Lagarde, M. M., Cox, B. C., Fang, J., Taylor, R., Forge, A., and Zuo, J. (2013). Selective ablation of pillar and deiters' cells severely affects cochlear postnatal development and hearing in mice. J. Neurosci. 33, 1564-1576. doi: 10.1523/ JNEUROSCI.3088-12.2013

Lammich, S., Okochi, M., Takeda, M., Kaether, C., Capell, A., Zimmer, A. K., et al. (2002). Presenilin-dependent intramembrane proteolysis of CD44 leads to the liberation of its intracellular domain and the secretion of an $\mathrm{A} \beta$-like peptide. J. Biol. Chem. 277, 44754-44759. doi: 10.1074/jbc.M206872200

Lanford, P. J., Lan, Y., Jiang, R., Lindsell, C., Weinmaster, G., Gridley, T., et al. (1999). Notch signalling pathway mediates hair cell development in mammalian cochlea. Nature 21, 289-292. doi: 10.1038/6804

Lanford, P. J., Shailam, R., Norton, C. R., Ridley, T., and Kelley, M. W. (2000). Expression of Math1 and HES5 in the cochleae of wildtype and Jag2 mutant mice. J. Assoc. Res. Otolaryngol. 1, 161-171. doi: 10.1007/s101620010023

Li, W., Wu, J., Yang, J., Sun, S., Chai, R., Chen, Z.-Y., et al. (2015). Notch inhibition induces mitotically generated hair cells in mammalian cochleae via activating the Wnt pathway. Proc. Natl. Acad. Sci. U.S.A. 112, 166-171. doi: 10.1073/pnas. 1415901112

Liu, Z., Owen, T., Fang, J., and Zuo, J. (2012). Overactivation of notch1 signaling induces ectopic hair cells in the mouse inner ear in an age-dependent manner. PLoS One 7:e34123. doi: 10.1371/journal.pone.0034123

Ludwig, A., Schlierf, B., Schardt, A., Nave, K. A., and Wegner, M. (2004). Sox10rtTA mouse line for tetracycline-inducible expression of transgenes in neural crest cells and oligodendrocytes. Genesis 40, 171-175. doi: 10.1002/gene.20083

Maass, J. C., Gu, R., Basch, M. L., Waldhaus, J., Lopez, E. M., Xia, A., et al. (2015). Changes in the regulation of the Notch signaling pathway are temporally 
correlated with regenerative failure in the mouse cochlea. Front. Cell. Neurosci. 9:110. doi: 10.3389/fncel.2015.00110

Maass, J. C., Gu, R., Cai, T., Wan, Y. W., Cantellano, S. C., Asprer, J. S. T., et al. (2016). Transcriptomic analysis of mouse cochlear supporting cell maturation reveals large-scale changes in Notch responsiveness prior to the onset of hearing. PLoS One 11:e0167286. doi: 10.1371/journal.pone.01 67286

Madisen, L., Zwingman, T. A., Sunkin, S. M., Oh, S. W., Zariwala, H. A., Gu, H., et al. (2010). A robust and high-throughput Cre reporting and characterization system for the whole mouse brain. Nat. Neurosci. 13, 133-140. doi: 10.1038/nn. 2467

Marambaud, P., Shioi, J., Serban, G., Georgakopoulos, A., Sarner, S., Nagy, V., et al. (2002). A presenilin- $1 / \gamma$-secretase cleavage releases the E-cadherin intracellular domain and regulates disassembly of adherens junctions. EMBO J. 21, 1948-1956. doi: 10.1093/emboj/21.8.1948

Marambaud, P., Wen, P. H., Dutt, A., Shioi, J., Takashima, A., Siman, R., et al. (2003). A CBP binding transcriptional repressor produced by the PS1/is an element of-cleavage of N-cadherin is inhibited by PS1FAD mutations. Cell 114, 635-645. doi: 10.1016/j.cell.2003.08.008

McGovern, M. M., Brancheck, J., Grant, A. C., Graves, K. A., and Cox, B. C. (2017). Quantitative analysis of supporting cell subtype labeling among creer lines in the neonatal mouse cochlea. J. Assoc. Res. Otolaryngol. 18, 227-245. doi: 10.1007/s10162-016-0598-0

Mellado Lagarde, M. M., Wan, G., Zhang, L., Gigliello, A. R., McInnis, J. J., Zhang, Y., et al. (2014). Spontaneous regeneration of cochlear supporting cells after neonatal ablation ensures hearing in the adult mouse. Proc. Natl. Acad. Sci. U.S.A. 111, 16919-16924. doi: 10.1073/pnas.1408064111

Mizutari, K., Fujioka, M., Hosoya, M., Bramhall, N., Okano, H. J., Okano, H., et al. (2013). Notch inhibition induces cochlear hair cell regeneration and recovery of hearing after acoustic trauma. Neuron 77, 58-69. doi: 10.1016/j.neuron.2012. 10.032

Morrison, A., Hodgetts, C., Gossler, A., Hrabé De Angelis, M., and Lewis, J. (1999). Expression of deltal and serrate1 (Jagged 1) in the mouse inner ear. Mech. Dev. 84, 169-172. doi: 10.1016/S0925-4773(99)00066-0

Mulvaney, J., and Dabdoub, A. (2012). Atoh1, an essential transcription factor in neurogenesis and intestinal and inner ear development: function, regulation, and context dependency. J. Assoc. Res. Otolaryngol. 13, 281-293. doi: 10.1007/ s10162-012-0317-4

Murata, J., Ohtsuka, T., Tokunaga, A., Nishiike, S., Inohara, H., Okano, H., et al. (2009). Notch-Hes1 pathway contributes to the cochlear prosensory formation potentially through the transcriptional down-regulation of p27Kip1. J. Neurosci. Res. 87, 3521-3534. doi: 10.1002/jnr.22169

Murata, J., Tokunaga, A., Okano, H., and Kubo, T. (2006). Mapping of Notch activation during cochlear development in mice: implications for determination of prosensory domain and cell fate diversification. J. Comp. Neurol. 497, 502-518. doi: 10.1002/cne.20997

Ni, C., Murphy, M., Golde, T., and Carpenter, G. (2001). gamma -secretase cleavage and nuclear localization of ErbB-4 receptor tyrosine kinase. Science 294, 2179-2181. doi: 10.1126/science. 1065412

Oesterle, E. C., Campbell, S., Taylor, R. R., Forge, A., and Hume, C. R. (2008). Sox2 and Jagged1 expression in normal and drug-damaged adult mouse inner ear. J. Assoc. Res. Otolaryngol. 9, 65-89. doi: 10.1007/s10162-007-0106-7

Pan, W., Jin, Y., Chen, J., Rottier, R. J., Steel, K. P., and Kiernan, A. E. (2013). Ectopic expression of activated notch or SOX2 reveals similar and unique roles in the development of the sensory cell progenitors in the mammalian inner ear. J. Neurosci. 33, 16146-16157. doi: 10.1523/JNEUROSCI.315012.2013
Pan, W., Jin, Y., Stanger, B., Kiernan, A. E., and Martin, G. (2010). Notch signaling is required for the generation of hair cells and supporting cells in the mammalian inner ear. Proc. Natl. Acad. Sci. U.S.A. 107, 15798-15803. doi: $10.1073 /$ pnas.1003089107

Pfaffl, M. (2001). A new mathematical model for relative quantification in real-time RT-PCR. Nucleic Acids Res. 29, 16-21. doi: 10.1093/nar/29.9.e45

Stanger, B. Z., Datar, R., Murtaugh, L. C., and Melton, D. A. (2005). Direct regulation of intestinal fate by Notch. Proc. Natl. Acad. Sci. U.S.A. 102, 12443-12448. doi: 10.1073/pnas.0505690102

Stone, J. S., and Cotanche, D. A. (2007). Hair cell regeneration in the avian auditory epithelium. Int. J. Dev. Biol. 51, 633-647. doi: 10.1387/ijdb.072408js

Tateya, T., Imayoshi, I., Tateya, I., Ito, J., and Kageyama, R. (2011). Cooperative functions of Hes/Hey genes in auditory hair cell and supporting cell development. Dev. Biol. 352, 329-340. doi: 10.1016/j.ydbio.2011.01.038

Taylor, R. R., Jagger, D. J., and Forge, A. (2012). Defining the cellular environment in the organ of Corti following extensive hair cell loss: a basis for future sensory cell replacement in the cochlea. PLoS One 7:e30577. doi: 10.1371/journal.pone. 0030577

Walters, B. J., and Zuo, J. (2015). A Sox10rtTA/+ mouse line allows for inducible gene expression in the auditory and balance organs of the inner ear. J. Assoc. Res. Otolaryngol. 16, 331-345. doi: 10.1007/s10162-015-0517-9

Wan, G., Gómez-Casati, M. E., Gigliello, A. R., Charles Liberman, M., and Corfas, G. (2014). Neurotrophin-3 regulates ribbon synapse density in the cochlea and induces synapse regeneration after acoustic trauma. elife 3:e03564. doi: 10.7554/eLife.03564

White, P. M., Doetzlhofer, A., Lee, Y. S., Groves, A. K., and Segil, N. (2006). Mammalian cochlear supporting cells can divide and trans-differentiate into hair cells. Nature 441, 984-987. doi: 10.1038/nature04849

Yamamoto, N., Tanigaki, K., Tsuji, M., Yabe, D., Ito, J., and Honjo, T. (2006). Inhibition of Notch/RBP-J signaling induces hair cell formation in neonate mouse cochleas. J. Mol. Med. 84, 37-45. doi: 10.1007/s00109-005-0706-9

Yu, Y., Weber, T., Yamashita, T., Liu, Z., Valentine, M. B., Cox, B. C., et al. (2010). In vivo proliferation of postmitotic cochlear supporting cells by acute ablation of the retinoblastoma protein in neonatal mice. J. Neurosci. 30, 5927-5936. doi: 10.1523/JNEUROSCI.5989-09.2010

Zheng, J. L., Shou, J., Guillemot, F., Kageyama, R., and Gao, W. Q. (2000). Hes1 is a negative regulator of inner ear hair cell differentiation. Development 127 , 4551-4560.

Zine, A., Aubert, A., Qiu, J., Therianos, S., Guillemot, F., Kageyama, R., et al. (2001). Hes1 and Hes5 activities are required for the normal development of the hair cells in the mammalian inner ear. J. Neurosci. 21, 4712-4720. doi: 10.1523/JNEUROSCI.21-13-04712.2001

Conflict of Interest Statement: BC is a consultant and MR is a part-time employee of Turner Scientific, LLC.

The other authors declare that the research was conducted in the absence of any commercial or financial relationships that could be construed as a potential conflict of interest.

Copyright (c) 2018 McGovern, Zhou, Randle and Cox. This is an open-access article distributed under the terms of the Creative Commons Attribution License (CC BY). The use, distribution or reproduction in other forums is permitted, provided the original author(s) and the copyright owner are credited and that the original publication in this journal is cited, in accordance with accepted academic practice. No use, distribution or reproduction is permitted which does not comply with these terms. 